\title{
Imbalances in Prefrontal Cortex CC-Homer1 versus CC-Homer2 Expression Promote Cocaine Preference
}

\author{
Alexis W. Ary, ${ }^{1}$ Kevin D. Lominac, ${ }^{1}$ Melissa G. Wroten, ${ }^{1}$ Amy R. Williams, ${ }^{1}$ Rianne R. Campbell, ${ }^{1}$ Osnat Ben-Shahar, ${ }^{1}$ \\ Georg von Jonquieres, ${ }^{2}$ Matthias Klugmann, ${ }^{2}$ and Karen K. Szumlinski ${ }^{1}$ \\ ${ }^{1}$ Department of Psychological and Brain Sciences and the Neuroscience Research Institute, University of California at Santa Barbara, Santa Barbara, \\ California 93106-9660, and ${ }^{2}$ Translational Neuroscience Facility, School of Medical Sciences, University of New South Wales, Sydney, New South Wales \\ 2052, Australia
}

Homer postsynaptic scaffolding proteins regulate forebrain glutamate transmission and thus, are likely molecular candidates mediating hypofrontality in addiction. Protracted withdrawal from cocaine experience increases the relative expression of Homer2 versus Homer1 isoforms within medial prefrontal cortex (mPFC). Thus, this study used virus-mediated gene transfer strategies to investigate the functional relevance of an imbalance in mPFC Homer1/2 expression as it relates to various measures of sensorimotor, cognitive, emotional and motivational processing, as well as accompanying alterations in extracellular glutamate in C57BL/6J mice. mPFC Homer2b overexpression elevated basal glutamate content and blunted cocaine-induced glutamate release within the mPFC, whereas Homer2b knockdown produced the opposite effects. Despite altering mPFC glutamate, Homer2b knockdown failed to influence cocaine-elicited conditioned place preferences, nor did it produce consistent effects on any other behavioral measures. In contrast, elevating the relative expression of Homer2b versus Homer1 within mPFC, by overexpressing Homer2b or knocking down Homer1c, shifted the dose-response function for cocaine-conditioned reward to the left, without affecting cocaine locomotion or sensitization. Intriguingly, both these transgenic manipulations produced glutamate anomalies within the nucleus accumbens (NAC) of cocaine-naive animals that are reminiscent of those observed in cocaine experienced animals, including reduced basal extracellular glutamate content, reduced Homer $1 / 2$ and glutamate receptor expression, and augmented cocaine-elicited glutamate release. Together, these data provide novel evidence in support of opposing roles for constitutively expressed Homer1 and Homer2 isoforms in regulating mPFC glutamate transmission in vivo and support the hypothesis that cocaine-elicited increases in the relative amount of MPFC Homer2 versus Homer1 signaling produces abnormalities in NAC glutamate transmission that enhance vulnerability to cocaine reward.

\section{Introduction}

A significant amount of data supports dysregulated corticoaccumbens glutamate as underpinning various addiction-related behaviors (Gass and Olive, 2008; Knackstedt and Kalivas, 2009; Schmidt and Pierce, 2010; Wolf and Ferrario, 2010; Kalivas and Volkow, 2011). Efforts to understand the molecular mechanisms of cocaine-induced glutamate plasticity revealed critical roles for the Homer $1 \mathrm{~b} / \mathrm{c}$ and Homer2a/b members of the Homer family of postsynaptic scaffolding proteins for basal, as well as cocaine-induced changes in, extracellular glutamate within both the nucleus accumbens (NAC) and prefrontal cortex

Received April 9, 2012; revised Jan. 23, 2013; accepted Feb. 18, 2013.

Author contributions: A.W.A. and K.K.S. designed research; A.W.A., K.D.L., M.G.W., A.R.W., R.R.C., G.V.-J., and K.K.S. performed research; M.K. contributed unpublished reagents/analytic tools; A.W.A., K.D.L., M.G.W., and K.K.S. analyzed data; A.W.A., K.D.L., M.G.W., A.R.W., O.B.-S., G.V.-J., M.K., and K.K.S. wrote the paper.

This work was funded by NIH Grant DA024038 (K.K.S.), a NARSAD grant (K.K.S.), an NIH National Research Service Award predoctoral fellowship (to A.W.A.), and an Australian Research Council Future Fellowship (to M.K.). We thank Dr. Tod E. Kippin for his helpful comments during the preparation of this report, as well as the National Institute on Drug Abuse for a generous donation of cocaine for these studies.

Correspondence should be addressed to Dr. Karen K. Szumlinski, Department of Psychological and Brain Sciences, University of California at Santa Barbara, Santa Barbara, CA 93106-9660. E-mail: karen.szumlinski@psych.ucsb.edu. DOI:10.1523/JNEUROSCI.1727-12.2013

Copyright $\odot 2013$ the authors $\quad 0270-6474 / 13 / 338101-13 \$ 15.00 / 0$
(PFC) (Szumlinski et al., 2008a). Homer proteins contain an $\mathrm{N}$-terminal Ena/VASP1 homology domain that interacts with a PPXXFR motif located on various postsynaptic density (PSD) proteins, including Group 1 metabotropic glutamate receptors (mGluRs) and certain downstream effectors. Constitutively expressed Homers also contain a carboxyl-terminal coiled-coil (CC) structure, allowing for self-assembly (Hayashi et al., 2006) and the aggregation of PSD proteins (Shiraishi-Yamaguchi and Furuichi, 2007; Szumlinski et al., 2008a). Withdrawal from a history of cocaine exposure, lowers both CC-Homer 1 and CC-Homer2 isoforms within NAC (Swanson et al., 2001; Ary and Szumlinski, 2007; Ben-Shahar et al., 2009; Ghasemzadeh et al., 2009b; but see Knackstedt et al., 2010a) and this adaptation is critical for cocaine-induced anomalies in NAC extracellular glutamate and the manifestation of drug-taking and drug-seeking, as well as psychomotor hyperactivity (Ghasemzadeh et al., 2003; Szumlinski et al., 2004, 2005b, 2006; Knackstedt et al., 2010).

In contrast to the NAC, repeated noncontingent cocaine experience elevates medial (mPFC) Homer2 levels during protracted withdrawal (Ary and Szumlinski, 2007). Although an earlier report indicated only a modest effect of cocaine self- 
administration on mPFC Homer2 expression (Ben-Shahar et al., 2009), more recent studies revealed a subregion-selective effect of self-administered cocaine upon PFC Homer2 expression, with increases in protein expression only in the more ventral aspects of this structure (i.e., in tissue homogenate from infralimbic and ventral prelimbic cortices) (A. T. Gould, unpublished observations). Thus, although there still exists a considerable knowledge gap vis-a-vis the pharmacological parameters required to elicit cocaine-induced changes in PFC Homer2 expression, it would appear that the imbalance in mPFC Homer1/2 expression observed in cocaine-experienced animals during protracted withdrawal reflects a pharmacodynamic response to cocaine. This raises questions as to the functional relevance of this Homer1/2 imbalance for corticoaccumbens glutamate and behavior, particularly when one considers that Homer1, but not Homer2, knockout $(\mathrm{KO})$ mice exhibit anomalies in PFC extracellular glutamate and in emotional, motivational, and sensorimotor processing (Szumlinski et al., 2004, 2005a; Lominac et al., 2005), but both KO strains exhibit changes in NAC glutamate and cocaineelicited changes in behavior that are akin to those observed in cocaine-experienced rodents (Szumlinski et al., 2004).

Thus, we sought to determine how producing an imbalance in Homer 1/2 expression might impact indices of forebrain extracellular glutamate and influence behavioral measures of emotionality, cognitive function, sensorimotor processing, and the motivational valence of both cocaine and nondrug reinforcers. It was hypothesized that an increase in the relative expression of $\mathrm{mPFC}$ Homer2 versus CC-Homer1 isoforms dysregulates corticoaccumbens glutamate transmission to promote cocaine preference. This study provides the first indication of opposing roles for CCHomer isoforms in regulating $\mathrm{mPFC}$ glutamate in vivo and provides novel evidence that imbalances in mPFC Homer1/2 expression is indeed sufficient to elicit glutamate dysfunction within the NAC and heighten the drive for cocaine-relevant environmental stimuli.

\section{Materials and Methods}

\section{Subjects}

Subjects were adult C57BL/6J male mice ( 8 weeks of age; $25-30 \mathrm{~g}$ ) bred at the University of California, Santa Barbara. With the exception of the sucrose drinking experiment, in which mice were singled-housed, for all other studies, animals were group-housed in polyethylene cages in a temperature $\left(25^{\circ}\right)$ and humidity $(71 \%)$ controlled vivarium under a $12 \mathrm{~h}$ dark/light cycle (lights off: 7:00 A.M.) with food and water available $a d$ libitum. Experimental protocols, as well as housing and animal care, were consistent the guidelines provided by the National Institute of Health (NIH) Guide for Care and Use of Laboratory Animals. All experiments were approved by the Institutional Animal Care and Use Committee of University of California, Santa Barbara.

\section{Surgical procedures}

Bilateral guide cannulae were surgically implanted above the PFC or the NAC of mice, using procedures identical to those previously used by our group (Lominac et al., 2005; Cozzoli et al., 2009). All surgeries were conducted under isoflourane anesthesia, with oxygen as the carrier gas. A Kopf stereotaxic device held the animal's head level and holes were drilled based on coordinates from bregma. For PFC experiments, 20 gauge stainless steel guide cannulae $(7 \mathrm{~mm}$ long; Small Parts) were implanted above the mPFC (AP: $+2.0 \mathrm{~mm}$; ML: \pm 0.5 mm; DV: $-1.0 \mathrm{~mm}$ ) (Paxinos and Franklin, 2007). For NAC experiments, guide cannulae (10 mm long; Small Parts) were implanted above the NAC shell (AP: $+1.3 \mathrm{~mm}$; ML: $\pm 1.0 \mathrm{~mm}$; DV: $-2.3 \mathrm{~mm}$ ) (Franklin and Paxinos, 2007). Guide cannulae were fixed to the skull with dental resin, surgical incisions were closed with a tissue adhesive, and dummy cannulae (24 gauge; length equivalent to guide cannulae) were placed inside guide cannulae to prevent contamination or block- ade. Animals were allowed a minimum of $5 \mathrm{~d}$ recovery before the start of experimental procedures.

\section{$A A V$ vectors and microinjection}

The generation of adeno-associated viruses AAVs carrying Homer $2 b$ cDNA and AAVs carrying small hairpin RNAs (shRNAs) against Homer $2 b$ or Homer $1 c$ were previously described in detail (Szumlinski et al., 2004; Klugmann et al., 2005; Lominac et al., 2005; Klugmann and Szumlinski, 2008; Cozzoli et al., 2009). In brief, for the cDNA-Homer2b $\mathrm{AAV}$, the PCR product for Homer2b was expressed as an $\mathrm{N}$-terminal fusion protein with a hemagglutinin (HA)-tag in a rAAV backbone containing the $1.1 \mathrm{~kb}$ CMV enhancer/chicken-actin (CBA) promoter, $800 \mathrm{bp}$ human interferon scaffold attachment region inserted $5^{\prime}$ of the promoter, the woodchuck posttranscriptional regulatory element (WPRE), and the bovine growth hormone polyA flanked by inverted terminal repeats (cDNA-Homer2b). AAV pseudotyped vectors (virions containing a 1:1 ratio of AAV1 and AAV2 capsid proteins with AAV2 intertrigeminal regions) were generated. For shRNA-Homer2b and shRNA-Homer1c, the reporter gene encoding green fluorescent protein (GFP), and the mouse U6 RNA polymerase III (U6) promoter upstream of the CBA promoter was added to our standard expression cassette, allowing for insertion or the simple replacement of short hairpin RNA (shRNA) cassettes, respectively (Klugmann and Szumlinski, 2008, their schematics of these cassettes). Depending upon the study, control vectors carried GFP, an empty cassette (Empty) or a scrambled vector against eGFP (Scrambled) to ensure that AAV infusion alone did not alter any behavioral or neurochemical measures examined. For these control AAVs, the same AAV-CBA-WPRE-bGH backbone was used. All of these different control AAVs have been used in previous studies by our laboratory and none of them significantly influenced any behavioral or neurochemical measure studied to date (Szumlinski et al., 2004, 2005b, 2006, 2008b; Lominac et al., 2005; Cozzoli et al., 2009, 2012; Goulding et al., 2011).

Stereotaxic procedures for AAV delivery in vivo were similar to those previously described by our group (Szumlinski et al., 2004; Cozzoli et al., 2009, 2012; Goulding et al., 2011). For mPFC microdialysis and behavioral experiments, 1 week after surgery, 33 gauge injector cannulae ( 9 $\mathrm{mm}$ long) were inserted bilaterally into the $\mathrm{mPFC}$ and AAVs were infused at a rate of $0.1 \mu \mathrm{l} / \mathrm{min}$ for $5 \mathrm{~min}$ (total vol $=0.50 \mu \mathrm{l} / \mathrm{side}$ ). Depending upon the experiment, mice received infusions of titer-matched AAV vectors $\left(1 \times 10^{12}\right.$ vector genomes $\left./ \mathrm{ml}\right)$ carrying Homer2b-cDNA, two different Homer2b-shRNAs, Homer1c-shRNA or a control vector (GFP, Empty or Scrambled). To assess for virus dose-dependent effects of altering Homer2 expression within the $\mathrm{mPFC}$, another group of animals received infusions at a rate of $0.02 \mu \mathrm{l} / \mathrm{min}$ for $5 \mathrm{~min}$ (total vol $=0.10$ $\mu \mathrm{l} /$ side). To assay for intra-mPFC Homer manipulations upon NAC neurochemistry, mice slated for the NAC microdialysis experiment received intra-PFC AAV infusions during surgery for implantation of bilateral intra-NAC microdialysis guide cannulae. In this case, holes were drilled in the skull at the mPFC coordinates indicated above (see Surgical Procedures), injector cannulae were inserted bilaterally into the mPFC (i.e., DV: $-2.0 \mathrm{~mm}$ ) and mice received an AAV infusion at a rate of 0.1 $\mu \mathrm{l} / \mathrm{min}$ for $5 \mathrm{~min}$ (total vol $=0.50 \mu \mathrm{l} / \mathrm{side}$ ). Three weeks after AAV delivery, behavioral testing and microdialysis experiments were conducted. Assessment of transduction efficiency and viral spread was conducted as previously described (Szumlinski et al., 2004, 2005b, 2006, 2008b; Lominac et al., 2005; Cozzoli et al., 2009, 2012; Goulding et al., 2011). Transgene expression of Homer $1 \mathrm{c}$ and Homer $2 \mathrm{~b}$ within the $\mathrm{mPFC}$ was verified using standard immunohistochemical detection the HA tag $\mathrm{N}$-terminally fused to the Homer coding regions and examination of tissue under a light microscope. Transduction by AAV-GFP and AAV-shRNAs (expressing humanized renilla GFP) was verified by examining tissue for epifluorescence using a fluorescent microscope (Fig. 1).

\section{Drug-naive behavioral testing}

To assay for effects of our AAV treatments upon indices of emotional, motivational, sensorimotor, and cognitive processing in drug-naive mice, we tested our subjects in a behavioral test battery that included Porsolt swim test, Morris water maze, reactivity to novelty test, and pre- 


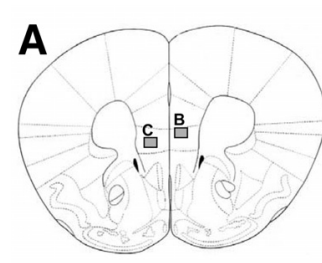

Control

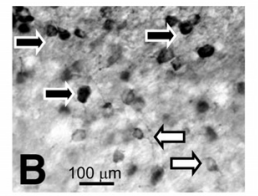

Homer2-shRNA

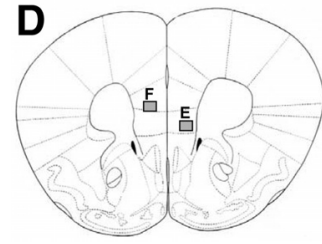

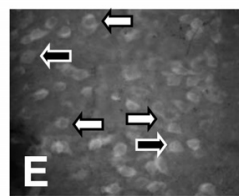

Homer2-cDNA

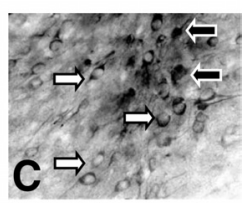

Homer1c-shRNA

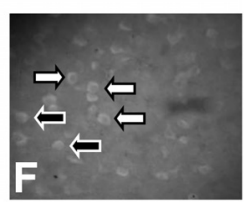

Figure 1. Comparison of AAV-mediated transduction within $\mathrm{mPFC} . \boldsymbol{A}-\boldsymbol{F}$, Representative schematics of the localization of AAV transduction of neurons $(\boldsymbol{A}, \boldsymbol{D})$ and micrographs of immunostaining for AAV-transfected HA-tagged GFP scrambled vector (Control) $(\boldsymbol{B})$ and Homer2b (Homer2-CDNA) (C) or representative micrographs of immunofluorescence for the GFP reporter in shRNA-Homer2b $(\boldsymbol{E})$ and shRNA-Homer $1 \mathrm{c}(\boldsymbol{F})$ within the mPFC of adult B6 mice at 10 weeks following AAV infusion ( $40 \times$ magnification of tissue section). Solid arrows in the micrographs indicate cytoplasmic and process staining, whereas open arrows indicate staining that is localized more so to the plasma membrane. The squares in the schematics of staining localization in $\boldsymbol{A}$ and $\boldsymbol{D}$ approximate the spread of AAVs infused in the micrograph subpanels indicated as determined by microscopic examination at $20 \times$ magnification.

pulse inhibition (PPI) of acoustic startle. The order of behavioral testing was varied across replicates of animals.

Porsolt swim test. The impact of altering mPFC Homer2b expression upon "behavioral despair" was assessed via a Porsolt swim test, where floating serves as a measure of learned helplessness (Porsolt et al., 1977). As previously described by our group (Szumlinski et al., 2004), mice were placed into a pool (30 cm in diameter; $45 \mathrm{~cm}$ high) filled with roomtemperature water up to $35 \mathrm{~cm}$ and allowed to swim for a total of $15 \mathrm{~min}$. In $20 \mathrm{~s}$ intervals, behavior was scored by an experimenter as either swimming (front and/or back paws mobile), floating (both front and back paws immobile), or climbing (swimming with forepaws making contact with the walls of the pool). Latency to first float was also determined using a stopwatch. The following day, mice were reintroduced to the pool for $5 \mathrm{~min}$ and their behavior and latency to float were again recorded. Data are expressed as percentage total of each incidence recorded. Each session's data were analyzed independently using a univariate ANOVA across the AAV infusion factor.

Morris water maze. Spatial reference learning and memory were examined using the Morris water maze paradigm. Procedures used were identical to those previously described (Bimonte et al., 2003; Szumlinski et al., 2004). A stainless steel circular tank $(200 \mathrm{~cm}$ in diameter, $60 \mathrm{~cm}$ in height) served as the maze, with salient extra maze cues located on all four walls of the room in which the maze was located. The inside of the tank was painted white, filled with room-temperature water to a depth of 50 $\mathrm{cm}$, and a clear platform was placed in the tank, with its location remaining fixed throughout the course of the experiment. For $14 \mathrm{~d}$, mice trained twice per day to locate the hidden platform. During each trial, mice were randomly placed in the pool at one of the four compass points and swimming was recorded digitally by a video camera mounted on the ceiling directly above the pool (ANY-Maze, Stoelting). Training sessions were $30 \mathrm{~s}$ in duration; if the mice were unable to locate the platform during the allotted time, they were guided to the platform where they remained for $30 \mathrm{~s}$. At $24 \mathrm{~h}$ and 1 week after the last training trial, memory probe tests were performed, where the platform was removed and the amount of time taken by the mouse to swim toward the platform location $(>120 \mathrm{~s})$ was recorded. Additionally, the total amount of time the mice spent swimming in the vicinity of the platform location was recorded. The data during training were analyzed using an AAV $\times$ Training Day $\times$ Trial ANOVA, with repeated measures on the Day and Trial factors. The data during each probe test were analyzed using a univariate ANOVA with AAV as the between-subjects factor.
Reactivity to novel objects. To assess for effects of our manipulations on anxiety, a novel object test was conducted, similar to that previously described in Szumlinski et al. (2005a). Mice were placed into a cylindrical tub $(200 \mathrm{~cm}$ in diameter, $60 \mathrm{~cm}$ in height) containing 1 small, inedible object for $2 \mathrm{~min}$. Animals were allowed to explore the object in the tub and both the number of contacts the mice made with the object and the amount of time the mice spent investigating the object (as defined by forepaw or snout contact with an object) were recorded by an experimenter. Data were analyzed using a univariate ANOVA across the AAV factor.

Prepulse inhibition of acoustic startle. The impact of PFC Homer2 expression upon sensorimotor gating was assessed via prepulse inhibition of acoustic startle. The apparatus and procedures used were identical to those previously described at length in Szumlinski et al. (2005a). Six trial types were offered: startle pulse (st110, $110 \mathrm{~dB} / 40 \mathrm{~ms}$ ), low prepulse stimulus given alone (st74, $74 \mathrm{~dB} / 20 \mathrm{~ms}$ ), high prepulse stimulus given alone (st $90,90 \mathrm{~dB} / 20 \mathrm{~ms}$ ), low or high prepulse stimulus given $100 \mathrm{mil}-$ liseconds before the onset of the startle pulse (pp74 and pp90, respectively) and no acoustic stimulus (st0; only background noise). All trials were presented randomly; st 0, st $110, \mathrm{pp} 74$, and pp 90 trials were given 10 times, whereas st 74 and st 90 were presented five times. Background noise in each chamber was $70 \mathrm{~dB}$ and the average intertrial interval lasted $15 \mathrm{~s}$. Data for startle amplitude were averaged across stimulus trials and then analyzed by an AAV infusion $\times$ stimulus ANOVA with repeated measures on the stimulus factor (st0, st74, st90, pp74, and pp90). Each animal's percentage inhibition for the $110 \mathrm{~dB}$ startle by the 74 and $90 \mathrm{~dB}$ prepulse intensities were calculated and data were analyzed by an AAV X Intensity ANOVA with repeated measures on the intensity factor (74 vs $90 \mathrm{~dB})$.

\section{Cocaine-conditioned place preference}

To determine the relevance of our reported cocaine-induced increase in mPFC Homer2 versus Homer1 expression (Ary and Szumlinski, 2007) for cocaine-induced changes in behavior, the effects of manipulating $\mathrm{mPFC}$ Homer2b levels upon cocaine reward and locomotor sensitization were assessed using a unbiased conditioned place preference (CPP) procedure (Szumlinski et al., 2007; Penzner et al., 2008). The CPP paradigm was selected for the study of AAV interactions with cocaine for its procedural simplicity, the ability to index both the positive and negative motivational valence of cocaine-associated cues and the ability to index both cocaine reward and locomotor activity. To elicit a cocaine CPP, mice were conditioned in a two-compartment apparatus where the compartments were tactilely (floor texture) and visually (wall pattern) distinct. Behavior was recorded throughout the experiment using a digital video-tracking system. Conditioning commenced with a 15 min habituation session to familiarize the animals to the entire apparatus. Animals received intraperitoneal (i.p.) cocaine injections $(3,15$, or $30 \mathrm{mg} / \mathrm{kg}$; a generous gift from National Institute on Drug Abuse, Bethesda, MD) and were then confined to one compartment for $15 \mathrm{~min}$. On alternating days, the mice were injected with an equivalent volume of saline $(\mathrm{vol}=0.01$ $\mathrm{ml} / \mathrm{g}$ body weight) and confined for $15 \mathrm{~min}$ to the other compartment. Following the fourth and final cocaine pairing, animals had free-access to the entire apparatus in a drug-free state during a 15 min postconditioning test. Amount of time spent on the cocaine-paired versus saline-paired compartment during the post-conditioning test served to index cocaine reward. The CPP data were analyzed using an AAV X Dose $X$ Side ( paired vs unpaired) ANOVA, with repeated measures on the Side factor. To determine the presence or absence of a CPP, significant interactions were deconstructed along the AAV and Dose factors and paired $t$ tests were conducted within each AAV group. For clarity, the CPP data are represented graphically as "Occupancy Difference"; that is, the difference in time spent on the cocaine-paired versus cocaine-unpaired compartment on the post-conditioning test.

\section{Sucrose preference testing}

We also assayed for the influence of our AAVs upon indices of natural reward by testing for sucrose drinking under free-access, two-bottle choice conditions in the home cage and a sucrose CPP. The procedures for the two-bottle choice sucrose drinking experiment were similar to 
those used in previous alcohol studies conducted in our laboratory (Szumlinski et al., 2005b, 2008b). For this, single-housed mice had $24 \mathrm{~h}$ access to two identical $50 \mathrm{ml}$ sipper tubes containing either water or a $5 \%$ sucrose solution. The total amount of water and sucrose solution consumed was determined by bottle weight before and after the $24 \mathrm{~h}$ consumption period over $4 \mathrm{~d}$, the average intake was calculated respectively on a milliliter per kilogram and a gram per kilogram body weight basis, and the data were analyzed by a univariate ANOVA across the AAV factor.

We used the same CPP apparatus for the sucrose CPP study as described (see above, Cocaine-conditioned place preference). On the first day of the experiment, animals were allowed $30 \mathrm{~min}$ free-access to both compartments to habituate them to the apparatus. Sucrose CPP was induced via 8 pairings of $5 \%$ sucrose solution in a drinking cup in one compartment, and on alternating days, 8 pairings of water in a drinking cup in the other compartment based on procedures used by other groups in rats (McAlonan et al., 1993). On the day after final pairing, animals were given free-access to the apparatus with no sucrose or water present for $30 \mathrm{~min}$ in a post-conditioning test. The data for the postconditioning test were analyzed using an AAV X Side (paired vs unpaired) ANOVA, with repeated measures on the Side factor.

\section{In vivo microdialysis}

Cocaine studies. In vivo microdialysis was conducted to assess the impact of altering the relative expression of Homer $1 \mathrm{c}$ and Homer2b within the $\mathrm{mPFC}$ on cocaine-induced glutamate release in the $\mathrm{mPFC}$ and its major glutamatergic afferent, the NAC. Conventional microdialysis was conducted for $1 \mathrm{~h}$ before, and $3 \mathrm{~h}$ immediately after, an intraperitoneal cocaine injection $(15 \mathrm{mg} / \mathrm{kg})$, as conducted previously by our group (Szumlinski et al., 2004, 2005b, 2007; Penzner et al., 2008). For all experiments, microdialysis probes (24 gauge; for mPFC: $10 \mathrm{~mm}$ in length with $\sim 1.0 \mathrm{~mm}$ active membrane; for NAC: $12 \mathrm{~mm}$ in length with $\sim 1.0$ $\mathrm{mm}$ active membrane) were lowered into the guide cannulae implanted above the intended region and perfused with artificial CSF $(146 \mathrm{nM} \mathrm{NaCl}$, $1.2 \mathrm{~mm} \mathrm{CaCl} 2,2.7 \mathrm{~mm} \mathrm{KCl}, 1.0 \mathrm{~mm} \mathrm{MgCl} 2, \mathrm{pH}=7.4$ ) at a rate of 2 $\mu \mathrm{l} / \mathrm{min}$. Dialysate collection began after $3 \mathrm{~h}$ of probe equilibration and occurred in $20 \mathrm{~min}$ intervals. Dialysate was stored at $-80^{\circ} \mathrm{C}$ until analysis by HPLC (see below, HPLC). For the mPFC studies, microdialysis probe localization was determined during histological examination for AAV transduction (see above) and revealed probe localization primarily within the more ventromedial aspect of the PFC (infralimbic and ventral prelimbic cortex), with a few probes placed within the more dorsal prelimbic cortex (see Fig. 3E). For the NAC studies, microdialysis probe localization within the NAC was verified using standard cresyl violet staining procedures, followed by examination of tissue under light microscope and revealed probe localization primarily to the shell subregion or to the interface between the shell and core subregions (see Figs. 5D, $6 E)$. The average baseline neurotransmitter levels during the hour before cocaine injection were calculated and analyzed using a univariate ANOVA, followed by LSD post hoc tests when appropriate. The data for the cocaine-induced change in extracellular glutamate were analyzed using an AAV X Time ANOVA, with repeated measures across the Time factor (20 min intervals; 3 baseline and 9 post-cocaine). Significant interactions were deconstructed along the AAV factor to determine the presence or absence of a cocaine effect, followed by $t$ tests with corrections for multiple-comparisons.

No net flux for basal glutamate. To assess whether altering PFC Homer levels affected basal extracellular glutamate in the mPFC or NAC, no net-flux microdialysis procedures were conducted in drug-naive animals using procedures similar to those previously described (Szumlinski et al., 2004, 2005a, 2008b; Lominac et al., 2005, 2012; Kapasova and Szumlin-
B
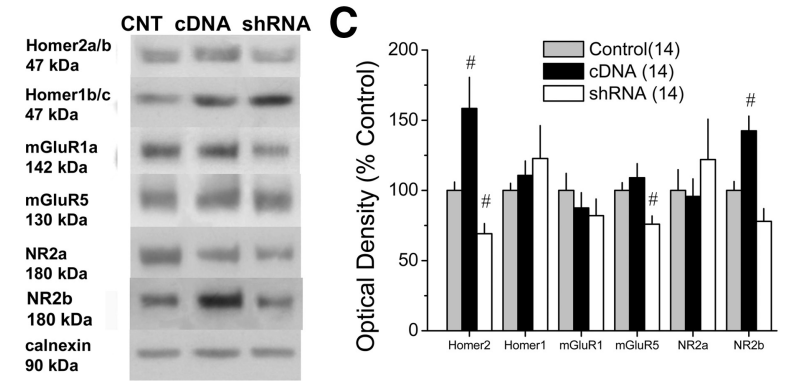

Figure 2. Protein changes within the mPFC elicited by AAV-mediated manipulations of mPFC Homer2b levels. $\boldsymbol{A}$, Schematic of the relative size of the micropunch used to dissect out the tissue surrounding the AAV microinjection site within the $\mathrm{mPFC}$ to overexpress Homer2b (cDNA) or shRNA to knockdown Homer2b (shRNA). The representative blots are from adjacent lanes on the same gel. Mice were killed at least 3 weeks after intra-mPFC AAV infusion. C, Summary of the change in protein expression the different intra-mPFC AAV treatments, expressed as a percentage of the average protein expression of CNT mice. ompared with controls, cDNA infusion elevated NR2b expression, whereas shRNA reduced mGluR5 expression ( $n=14$ /AAV er two groups, LSD post hoc tests.

ski, 2008; Ben-Shahar et al., 2012). Probe implantation and equilibration procedures were identical to those described for conventional microdialysis above. After $1 \mathrm{~h}$ of baseline sample collection, increasing concentrations of glutamate $(2.5,5$, and $10 \mu \mathrm{M})$ were infused through the probe in ascending order for $1 \mathrm{~h}$ each. Dialysate was collected every $20 \mathrm{~min}$ and samples were stored at $-80^{\circ} \mathrm{C}$ before HPLC analysis (see below, HPLC). Linear regression analyses were conducted on the plot of the average net flux of glutamate at each glutamate concentration versus the concentration of glutamate infused through the probe and the point of no net flux ( $y=0$; estimate of basal extracellular levels of glutamate), as well as the slope of regression lines (estimate of glutamate clearance), were determined and analyzed using an univariate ANOVA across the AAV factor, followed by LSD post hoc tests when appropriate (for Homer2b) or Student's $t$ tests (for Homer1c).

HPLC. The HPLC system and procedures for the electrochemical detection of glutamate in the dialysate of mice, as well as the chromatographic analysis of the data, were identical to those previously recently by our group Goulding et al., 2011; Ben-Shahar et al., 2012; Lominac et al., 2012). The HPLC systems consisted of a Coularray detector, a Model 542 autosampler and a Model 582 solvent delivery systems (ESA), with a detection limit of $0.01 \mathrm{fg} / \mathrm{sample}$ ( $20 \mu \mathrm{l} / \mathrm{sample}$ onto column). The mobile phase consisted of $100 \mathrm{~mm} \mathrm{NaH} \mathrm{PO}_{4}, 22 \%$ methanol (v/v), 3.5\% acetonitrile $(\mathrm{v} / \mathrm{v}) \mathrm{pH}=6.75$ and glutamate was separated using a CAPCELL PAK C18 MG column ( $5 \mathrm{~cm}$; Shiseido), eluting at $1.8 \mathrm{~min}$. An ESA $5011 \mathrm{~A}$ analytical cell with two electrodes (E1, +150 mV; E2, +550 mV) detected glutamate, after precolumn derivatization with $o$-phthalaldehyde $(2.7 \mathrm{mg} / \mathrm{ml})$ using the autosampler. The glutamate content in each sample was analyzed by peak height and was compared with an external standard curve for quantification using ESA Coularray for Windows software.

\section{Immunoblotting}

Immunoblotting studies were conducted to (1) quantify AAV-induced changes in PFC Homer2 expression and (2) examine for AAV-induced alterations in Homer-associated glutamate receptors within both the mPFC (site of AAV infusion) and in the NAC. Homer proteins scaffold Group1 mGluRs and NMDA receptors within the postsynaptic density, but also regulate their trafficking from the endoplasmic reticulum (Shiraishi-Yamaguchi and Furuichi, 2007). Thus, conventional immunoblotting procedures were conducted on whole tissue homogenate to index simultaneously AAV-induced changes in both glutamate receptor and Homer expression. The tissue homogenization and immunoblotting procedures used were identical to those previously described by our group (Ary and Szumlinski, 2007; Szumlinski et al., 2008b; Ben-Shahar et al., 2009; Cozzoli et al., 2009, 2012; Goulding et al., 2011). For the immunoblotting study, mice were fitted with indwelling guide cannulae 
aimed $2 \mathrm{~mm}$ above the mPFC (see above) before AAV infusion, as in previous studies (Szumlinski et al., 2004, 2008b). After at least 3 weeks post-AAV infusion, $0.5 \mu \mathrm{l} /$ side of dye was microinjected into the PFC to more accurately determine the site of AAV infusion just before tissue collection using an 18 gauge micropunch (Fig. 2A). The NAC was also dissected out using forceps (see Fig. $5 F$ ). The samples were homogenized in a medium consisting of $0.32 \mathrm{~m}$ sucrose, $2 \mathrm{~mm}$ EDTA, 1\% w/v SDS, 50 $\mu \mathrm{M}$ phenyl methyl sulfonyl fluoride and $1 \mu \mathrm{g} / \mathrm{ml}$ leupeptin $(\mathrm{pH}=7.2$ ) and $50 \mathrm{~mm}$ sodium fluoride, $50 \mathrm{~mm}$ sodium pyrophosphate, $20 \mathrm{~mm}$ 2-glycerol phosphate, $1 \mathrm{~mm} p$-nitrophenyl phosphate, and $2 \mu \mathrm{M}$ microcystin LR were included to inhibit phosphatases. All samples were stored at $-80^{\circ} \mathrm{C}$ until immunoblotting analysis ensued.

Samples were subjected to a SDS-PAGE using 3-8\% Tris-acetate gels (Invitrogen). Proteins were transferred to PVDF membranes and preblocked with PBS containing 0.1\% (v/v) Tween 20 and 5\% (w/v) nonfat dried milk powder for a minimum of $1 \mathrm{~h}$ before overnight incubation with a primary antibody. Anti-Homer2a/b (Cosmo Bio; 1:1000 dilution), anti-Homer1b/c (GeneTex; 1:1000 dilution), anti-mGluR5 (Millipore; 1:1000 dilution), anti-NR2a and anti-NR2b (Calbiochem; 1:1000 dilution) rabbit polyclonal antibodies were used. A mouse polyclonal antimGluR1a antibody (BD Transduction Laboratories; 1:1000 dilution) was also used. After primary antibody incubation, membranes were washed and incubated with a horseradish peroxidase-conjugated goat anti-rabbit secondary antibody (Millipore; 1:40,000-1:80,000 dilution) or antimouse secondary antibody (Millipore; 1:40,000-1:80,000) for $90 \mathrm{~min}$. Membranes were then washed again and immunoreactive bands were detected by enhanced chemiluminescence using either ECL Plus (GE Healthcare) or Pierce SuperSignal West Femto (Fisher Scientific). To assess for protein loading and membrane transfer, a rabbit anti-calnexin polyclonal primary antibody (Stressgen) was used. Immunoreactivity of each protein was quantified using ImageJ (NIH). Protein/Calnexin ratios were used to normalize immunoreactivity of each protein with its respective calnexin value and for group comparisons; these data for experimental animals were expressed as a percentage of the GFP controls on each gel. All immunoblotting data were analyzed using univariate ANOVAs across the AAV factor and significant AAV effects were followed by LSD post hoc tests.

\section{Results \\ Histological verification of neuronal transduction by AAVs in mPFC and effects on mPFC protein expression}

Consistent with our earlier reports (Szumlinski et al., 2004, 2005b, 2006, 2008b; Lominac et al., 2005; Cozzoli et al., 2009; Goulding et al., 2011), immunohistochemical examination of the microinjection sites revealed neuronal transduction by our different AAV constructs that was restricted to within $1-1.5 \mathrm{~mm}$ the microinjection tip within the mPFC. Patterns of transduction were observed within the more ventral aspect of the MPFC, primarily within the ventral prelimbic cortex or at the interface between the prelimbic and infralimbic cortices (Fig. 1 $A, D$ ). It should be noted that, within each study, some animals $(n=1-2)$ exhibited transduction that was restricted to the infralimbic cortex, whereas no animals exhibited transduction within dorsal prelimbic or anterior cingulate cortex. As reported previously for the NAC (Cozzoli et al., 2009; Goulding et al., 2011), the pattern of transduction within the mPFC did not differ in any obvious manner across the different constructs, with staining of both cell bodies and processes apparent whether transduction was detected using an antibody against the hemagglutinin (HA) tag (Fig. 1 B, C; for Empty-Control, Homer2b-cDNA, respectively) or using fluorescent microscopy to visualize the GFP reporter (Fig. 1E, F, for Homer2b-shRNA, Homer1c-shRNA, respectively).

We also used immunoblotting to quantify the extent to which AAVs carrying GFP, Homer2b-cDNA or Homer2b-shRNA, infused 3 weeks prior, influenced Homer $2 \mathrm{a} / \mathrm{b}$ protein expression by dissecting out the area surrounding microinjector tip placement (Fig. 2A) and examined for the specificity of AAV-Homer2 effects by examining for changes in the total Homer $1 \mathrm{~b} / \mathrm{c}$ protein expression. As Homer2 deletion can influence the total protein expression of mGluRs (Szumlinski et al., 2004), we assayed also for changes in Group1 mGluR and NR2 subunit expression. Akin to our earlier reports for the NAC (Klugmann and Szumlinski, 2008; Goulding et al., 2011), mPFC Homer2b levels were bidirectionally regulated by our AAVs (Fig. $2 B, C)\left(F_{(2,39)}=9.00, p=\right.$ $0.001)$. Relative to controls, the cDNA construct elevated Homer2b levels by $\sim 50 \%$ ( $p<0.0001$; LSD post hoc tests) and the shRNA construct lowered levels by $\sim 40 \%$ ( $p=0.008$, LSD post hoc tests). Neither construct influenced mPFC levels of Homer1b/c $\left(F_{(2,42)}=0.57, p=0.6\right)$. Despite earlier evidence for coregulation of mGluR1a, NR2a and Homer2a/b within mPFC during cocaine withdrawal (Ary and Szumlinski, 2007), neither mGluR1a nor NR2a levels were affected by our transgenic manipulations of mPFC Homer2b expression (univariate ANOVAs: both $p$ values $>0.5$ ). However, relative to controls, mGluR5 levels were reduced significantly upon Homer2b knockdown, but not influenced by Homer2b overexpression $\left[F_{(2,39)}=5.38, p=\right.$ 0.009 ; LSD post hoc tests, Control $=\mathrm{cDNA}(p>0.05)>\operatorname{shRNA}$ $(p=0.02)]$. Conversely, NR2b levels were elevated by Homer2b overexpression, but only marginally reduced by Homer2b knockdown $\left[F_{(2,39)}=13.94, p<0.0001\right.$; LSD post hoc tests, Control $=\operatorname{shRNA}(p=0.08)<\operatorname{cDNA}(p=0.004)]$. These data are the first to demonstrate in vivo that $\mathrm{AAV}$-mediated transgenic manipulations of Homer2b expression within brain can influence the total protein expression of certain Homer interacting partners.

\section{PFC Homer 2 expression regulates basal and cocaine-induced glutamate release in the PFC}

To begin to understand the functional relevance of an increase in the relative expression of Homer2 versus Homer1 within mPFC, we conducted in vivo microdialysis studies to examine the effects of bidirectionally altering mPFC Homer2b expression using AAVs carrying Homer2b cDNA or 2 different shRNA constructs (Klugmann and Szumlinski, 2008) protein expression. Conventional in vivo microdialysis revealed a bidirectional effect of mPFC Homer2 manipulations upon baseline extracellular glutamate within this region (Fig. $3 A)\left(F_{(3,35)}=8.22, p<0.0001\right)$; Homer2b overexpression elevated, whereas Homer2b knockdown reduced, baseline PFC glutamate levels (LSD post hoc tests, $p$ values $<0.05$ ). As the two different shRNA constructs did not differ in the magnitude of their effect upon basal PFC glutamate (Fig. 3A) (LSD post hoc tests, $p>0.05$ ), the data for the shRNA groups were combined for all subsequent data analyses and only one shRNA construct was used in follow-up experiments.

Group differences were also observed regarding the capacity of an acute $15 \mathrm{mg} / \mathrm{kg}$ cocaine injection to elevate mPFC glutamate levels and the direction of the AAV effect upon cocaine-induced glutamate release was inverse to that observed for basal glutamate (Fig. $3 B$ ) (AAV effect: $F_{(2,33)}=4.32, p=0.02$; AAV X Time: $\left.F_{(22,363)}=6.28, p<0.0001\right)$. The distinctions in the cocaine responsiveness of $\mathrm{mPFC}$ extracellular glutamate in animals infused intra-mPFC with the different AAVs were even more pronounced when the data were expressed as a percentage change from baseline (Fig. $3 C$; data from Fig. $3 B$ normalized to baseline) $\left(\mathrm{AAV}\right.$ effect: $F_{(2,33)}=10.77,<0.0001$; AAV X Time: $F_{(22,363)}=$ $3.26, p<0.0001)$. As illustrated clearly in Figure $3 C$, the cocaine injection produced a moderate, but significant, rise in $\mathrm{mPFC}$ glutamate of control animals $\left(F_{(11,134)}=3.29, p<0.0001\right)$, 
and this effect was potentiated markedly in the Homer2-underexpressing mice $\left(F_{(11,77)}=3.54, p<0.00010\right)$. In contrast, glutamate levels dropped below baseline in the Homer2 overexpressing animals following cocaine injection $\left(F_{(11,143)}=\right.$ $6.10, p<0.0001)$. These data demonstrate that Homer2b actively and bidirectionally regulates both basal and cocaine-stimulated glutamate release in the $\mathrm{mPFC}$, raising the possibility that $\mathrm{mPFC}$ Homer2b expression may be critical for behaviors subserved by this region.

Based on the results for baseline glutamate (Fig. 3A), we next used no net-flux microdialysis approaches to quantify AAV-mediated changes in extracellular glutamate content and examine for potential effects upon glutamate clearance (Fig. 3D). No net-flux approaches confirmed the reduction in basal PFC glutamate levels by shRNA infusion; however, the rise in basal PFC glutamate by cDNA infusion was just shy of statistical significance $\left[y=0 ; F_{(2,30)}=4.23, p=0.03\right.$; LSD post hoc tests: Control $=$ cDNA $(p=$ $0.07)<\operatorname{shRNA}(p<0.05)]$. PFC Homer2b manipulation did not affect the slope of the linear regression (Fig. 3D) (univariate ANOVA, $p>0.5$ ), indicating no effect of Homer2 overexpression or underexpression on glutamate clearance within the mPFC.

\section{PFC Homer2 overexpression enhances cocaine-conditioned reward}

We next investigated the relevance of the imbalance in $\mathrm{mPFC}$ Homer $1 / 2$ expression for a cocaine CPP. Homer2b-cDNA infusion shifted the dose-response function for cocaine CPP to the left of both Homer2b-shRNA and control infused animals, whereas knocking down Homer2b expression did not affect cocaine CPP relative to controls (Fig. $4 A)($ AAV $\times$ Dose $\times$ Side ANOVA: $\left.F_{(4,89)}=2.91, p=0.03\right)$. Cocaine dose-dependently elicited place-conditioning in all three AAV groups, with the $3 \mathrm{mg} / \mathrm{kg}$ dose eliciting a moderate place preference in GFP controls, but a robust place preference in cDNA-infused animals (paired $t$ tests, GFP: $t_{(10)}=2.26, p=0.05$; cDNA: $t_{(7)}=4.70, p=0.002$; shRNA: $p=0.62)$. All groups exhibited significant place preference after conditioning with $15 \mathrm{mg} / \mathrm{kg}$ cocaine (paired $t$ tests, all $p$ values $<0.0001$ ), but the magnitude of the place preference exhibited by cDNA-infused mice was greater than that exhibited by their GFPinfused and shRNA-infused counterparts [one-way ANOVA, $F_{(2,38)}=7.76, p=0.002$; LSD post hoc tests: Control = shRNA $(p<0.05)<\mathrm{cDNA}(p>0.05)]$. However, the $30 \mathrm{mg} / \mathrm{kg}$ cocaine dose produced place preference in GFP-infused and shRNAinfused animals only (paired $t$ tests, GFP: $t_{(10)}=2.35, p=0.04$; cDNA: $p=0.68$; $\left.\operatorname{shRNA}_{(9)}=2.79, p=0.02\right)$. These behavioral data, coupled with earlier data from Homer2 KO mice (Szumlinski et al., 2004), indicate that mPFC Homer2b overexpression is sufficient, but not necessary, to increase sensitivity to the condi-
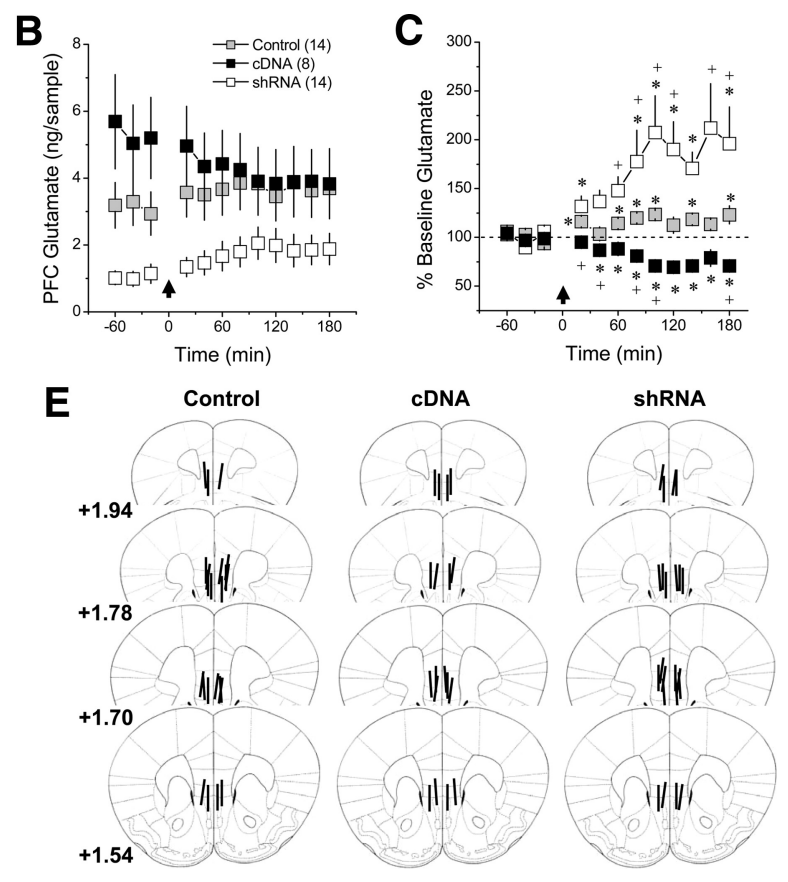

Figure 3. Glutamate changes within the mPFC elicited by AAV-mediated manipulations of mPFC Homer2b levels. $\boldsymbol{A}$, Summary study were infused with either scrambled nonsense vector or GFP. B, Summary of the effects of our AAVs on the time course of change in extracellular glutamate levels within the $\mathrm{mPFC}$ during baseline (time $-60-0 \mathrm{~min}$ ) and after a $15 \mathrm{mg} / \mathrm{kg}$, i.p., injection (arrow), indicating bidirectional effects of our Homer2b-targeting vectors upon both basal glutamate levels and represent the mean \pm SEM. ${ }^{*} p<0.05$ versus average baseline, paired $t$ tests, with corrections for multiple-comparisons; $p<$ strating no change in the clearance of glutamate from the probe (slope) by AAV infusion, but a significant shift in the point of no net in shRNA-infused mice ( $n=9-10 / A A V)$. $\boldsymbol{E}$, Schematic of the placements of the microdialysis probes probe placements for animals tested under conventional in vivo microdialysis procedures $(\boldsymbol{A}-\boldsymbol{C})$ were consistent with the placements illustrated in $\boldsymbol{E}$ (data not shown).

tioned rewarding properties of cocaine and to enhance cocaineseeking behavior.

\section{PFC Homer2 overexpression does not impact behavioral measures in drug-naive mice}

To determine whether or not the effects of PFC Homer2b overexpression on cocaine CPP generalized to natural reward, we also assayed the effects of altering mPFC Homer2 expression on sucrose reward in drug-naive animals using both a sucrose-induced CPP and a two bottle choice (water vs $5 \%$ sucrose) free-access, home-cage, drinking experiment. However, mPFC Homer2 overexpression did not facilitate the expression of a sucrose CPP (AAV X Side interaction, $p>0.05$ ), nor did it promote greater sucrose intake in the home cage (AAV X Concentration, $p>$ 0.05 ) (data not shown). Thus, the enhanced cocaine-conditioned reward observed in the CPP study (Fig. 4A) does not appear to reflect some general effect of $\mathrm{mPFC}$ Homer $2 \mathrm{~b}$ overexpression upon reward processing.

Earlier transgenic studies of mPFC Homer $1 \mathrm{a} / \mathrm{c}$ expression indicated necessary, but distinct, roles for these Homer isoforms in regulating sensorimotor, cognitive and emotional processing (Lominac et al., 2005). In contrast, the results of a similar behav- 


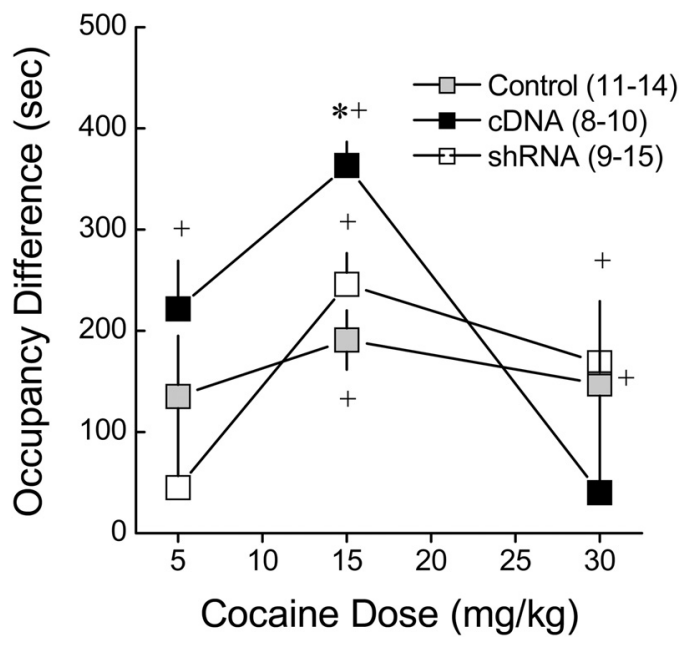

Figure 4. mPFC Homer2b overexpression potentiates cocaine-seeking. Summary of the effect of four pairings of $15 \mathrm{mg} / \mathrm{kg}$ cocaine upon the difference in the time spent (in seconds) on the cocaine-paired versus cocaine-unpaired side of the place-conditioning apparatus (Occupancy Difference) when animals were tested in a cocaine-free state. Groups of mice were infused intra-mPFC with AAVs carrying a GFP control vector or a nonsense scrambled control vector (Control; $n=11-14 /$ cocaine dose), CDNA-Homer2b (CDNA; $n=8-10 /$ cocaine dose) or shRNA-Homer2b (shRNA; $n=9-15 /$ cocaine dose), 3 weeks before the start of conditioning. ${ }^{*} p<0.05$ CDNA versus control, LSD post hoc tests; ${ }^{+} p<0.05$ Paired versus Unpaired (i.e., conditioning; paired $t$ tests). All data represent the mean \pm SEM.

ioral test battery revealed very few effects of our Homer2 AAV constructs (data not shown). In the Porsolt swim test, Homer2shRNA mice exhibited an increased latency to float on day 1 of testing (15 min test), but not $24 \mathrm{~h}$ later, compared with controls (AAV X Test: $F_{(3,31)}=3.16, p=0.04$; post hoc tests). However, altering $\mathrm{mPFC}$ Homer2 expression did not significantly affect measures of anxiety in a novel object test, nor did it influence the magnitude of an acoustic startle (ANOVAs, $p>0.05$ ). Finally, also different from an earlier report for mPFC Homerla/c overexpression (Lominac et al., 2005), mPFC Homer2 expression did not influence sensorimotor gating as measured by prepulse inhibition of acoustic startle (ANOVA, all main effects or interactions with AAV factor, $p>0.05$ ) nor did it influence learning or recall in a Morris water maze task (ANOVA, all main effects or interactions with AAV factor, $p>0.05)$. These data indicate that the effects of mPFC Homer2 overexpression upon cocaine reward are not likely related to changes in cognitive, emotional and sensorimotor processing.

\section{mPFC Homer 2 overexpression produces abnormalities in NAC extracellular glutamate}

In contrast to our robust effects upon mPFC basal extracellular glutamate (Fig. $3 A, D$ ), we detected only a modest effect of our mPFC AAV manipulations on the average basal glutamate levels in the NAC when assayed by conventional in vivo microdialysis approaches (one-way ANOVA, $p=0.06$ ). An inspection of Figure $5 A$ suggested that the modest AAV effect was attributable to a reduction in glutamate in animals infused with Homer2-cDNA and this finding was confirmed using quantitative microdialysis approaches (Fig. $4 C)(y=0)\left[F_{(2,23)}=4.74, p=0.02\right.$; LSD post hoc tests: Control $=\operatorname{shRNA}(p>0.05)>\operatorname{cDNA}(p=0.02)]$. The reduction in NAC basal glutamate observed in Homer2-cDNA animals was unrelated to changes in glutamate clearance, as no significant differences were observed for the slopes derived from the linear regression analysis of the data obtained under no netflux microdialysis procedures (Fig. 5C) (one-way ANOVA, $p=$
0.14). As a reduction in NAC extracellular glutamate levels is a neurochemical adaptation observed in animals with a history of repeated cocaine experience (Pierce et al., 1996; Baker et al., 2003; McFarland et al., 2003; Szumlinski et al., 2006; but see Madayag et al., 2010), these data provide novel evidence that mimicking the cocaine-induced rise in mPFC Homer2 expression (Ary and Szumlinski, 2007) is sufficient to elicit a "cocaine-like" alteration in basal extracellular glutamate within the NAC of drug-naive animals.

Lowered basal extracellular glutamate within the NAC of cocaine-experienced animals is associated with a heightened capacity of cocaine to elevate NAC glutamate levels (i.e., a sensitization of cocaine-induced glutamate release) (Pierce et al., 1996; Baker et al., 2003; McFarland et al., 2003; Szumlinski et al., 2004, 2006). Consistent with this inverse relation, mPFC Homer2 overexpression promoted glutamate release within the NAC, whereas mPFC Homer2 knockdown had no effect (Fig. 5A) (AAV X Time: $\left.F_{(22,198)}=3.56, p<0.0001\right)$. To better visualize the extent to which mPFC Homer2 overexpression facilitated cocainestimulated glutamate release, the data from Figure $5 A$ were expressed as a percentage change from baseline in Figure $4 B$. As is clear from the normalized data (Fig. 5B), an acute injection of 15 $\mathrm{mg} / \mathrm{kg}$ cocaine produced a modest reduction in NAC glutamate levels in both control and Homer2-shRNA animals, while this same injection produced a large rise in glutamate in NAC of Homer2-cDNA animals (AAV X Time: $F_{(22,198)}=4.93, p<$ $0.0001)$. Indeed, the results of follow-up analyses failed to indicate any cocaine effect upon NAC extracellular glutamate in Control or shRNA-infused animals (one-way ANOVAs, $p>0.05$ ), whereas cDNA-infused animals exhibited a marked change in NAC glutamate levels $\left(F_{(11,55)}=3.58, p<0.001\right.$; paired $t$ tests with corrections for multiple-comparisons). Thus, Homer $2 \mathrm{~b}$ overexpression within the $\mathrm{mPFC}$ produces abnormalities not only in basal, but also in cocaine-stimulated glutamate release, within the NAC that are strikingly similar to those reported previously in cocaine-experienced rodents.

\section{Manipulations of PFC Homer2 expression are sufficient to affect expression of homers and glutamate receptors within the NAC}

We also sought to determine whether or not altering $\mathrm{mPFC}$ Homer2 expression might also elicit a "cocaine-like" reduction in the expression of Homer proteins and their interacting glutamate receptors within the NAC. To test this hypothesis, NAC tissue was collected from drug-naive mice at 3 weeks after mPFC AAV infusion and immunoblotted for Homer1/2, mGluR1/5 and NR2a/b. As illustrated in Figure 5E, mPFC Homer2b overexpression lowered, whereas Homer2b knockdown failed to significantly affect, NAC levels of Homer2a/b, Homer1b/c, mGluR1, mGluR5, and NR2a [for Homer2: $F_{(2,42)}=4.42, p=0.02$, LSD post hoc tests, Control $>$ cDNA, $p=0.006$; for Homer 1: $F_{(2,42)}=5.62, p=0.007$, LSD post hoc tests, Control $=$ shRNA $>$ cDNA $(p=0.005)$; for mGluR1: $F_{(2,42)}=5.21, p=0.01$; for mGluR5: $F_{(2,42)}=7.42, p=0.002$; and NR2a: $F_{(2,42)}=7.49, p=0.002$; post hoc tests]. Altering PFC Homer2 levels also had a bidirectional effect upon NAC NR2b expression, with overexpression and underexpression producing respectively a moderate reduction and a significant elevation in subunit expression $\left(F_{(2,42)}=7.73, p=0001\right.$; post hoc tests). These data demonstrate that mimicking a cocaineinduced rise in PFC Homer2 expression is sufficient to produce "cocaine-like" reductions in NAC glutamate receptor and CC-Homer expression implicated previously in the man- 
ifestation of cocaine addiction-related behaviors (Swanson et al., 2001; Ghasemzadeh et al., 2003, 2009a,2009b; Szumlinski et al., 2004, 2005b, 2006; Ary and Szumlinski, 2007; Ben-Shahar et al., 2009; Knackstedt et al., 2010a).

mPFC Homer1c knockdown produces a cocaine and NAC glutamate phenotype similar to mPFC Homer2b overexpression

The above data strongly supports the notion that a cocaine-induced imbalance in the relative expression of $\mathrm{CC}$ Homer2 versus CC-Homer1 isoforms within the mPFC dysregulates corticoaccumbens glutamate transmission to promote cocaine-seeking behavior. To further test this hypothesis, we used an alternate strategy to create a CC-Homer1/2 imbalance by infusing mice intra-mPFC (0.5 $\mu \mathrm{l} /$ side) with AAVs carrying either a GFP control vector or Homerlc shRNA (Fig. 1D). Mice were then tested (3 weeks later) for alterations in cognitive and emotional processing, cocaine $\mathrm{CPP} /$ sensitization and extracellular levels of NAC glutamate, in a manner identical to that for mice infused with AAVs to manipulate mPFC Homer2b expression. As observed with mPFC Homer2 overexpression, $\mathrm{mPFC}$ Homer1c knockdown did not influence our measures of emotional processing when assayed by Porsolt swim test and novel object test, nor did it influence sensorimotor processing in our prepulse inhibition of acoustic startle paradigm (no main effects of, or interactions with, the AAV factor for all studies, $p>0.05$; data not shown). Likewise, mPFC Homerlc knockdown also did not influence locomotor activity in response to the initial exposure to the CPP apparatus nor did it influence saline-induced locomotion during conditioning (no main effects of, or interactions with, the AAV factor for all studies, $p>0.05$; data not shown). However, consistent with our hypothesis regarding a Homer1-Homer2 imbalance and cocaine-seeking, Homer1c knockdown potentiated a cocaine CPP in a manner akin to Homer2b overexpression (Fig. $5 A)\left(t_{(22)}=\right.$ $2.14, p=0.04)$, but it did not influence the locomotor-stimulating or locomotor-sensitizing effects of cocaine (Fig. 5B) (AAV X Injection: $p>0.05$ ). These data provide novel evidence for an important role for the balance between the expression of CC-Homer1 and CC-Homer2 isoforms within $\mathrm{mPFC}$ in regulating cocaine-seeking behavior and pose idiopathic or cocaine-elicited increases in the relative expression of Homer2 versus Homer1 as a molecular mechanism for increased vulnerability to the incentive motivational value of drug-associated contexts and cues during withdrawal.

As mPFC Homer1c knockdown was sufficient to potentiate cocaine-seeking in a manner akin to mPFC Homer2b overexparentheses in each panel.
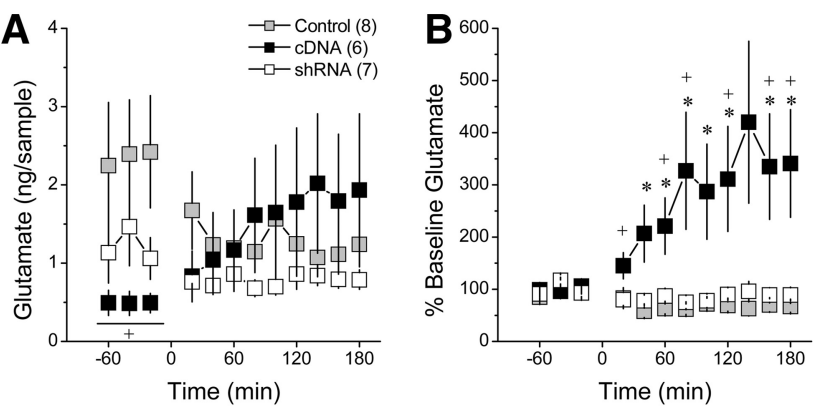

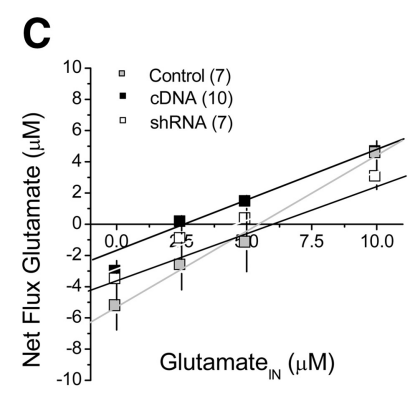

E
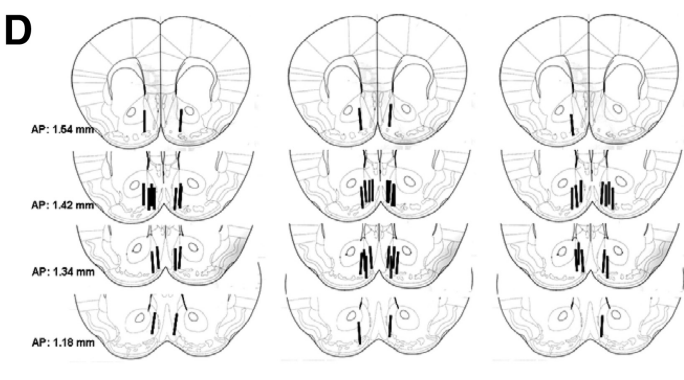
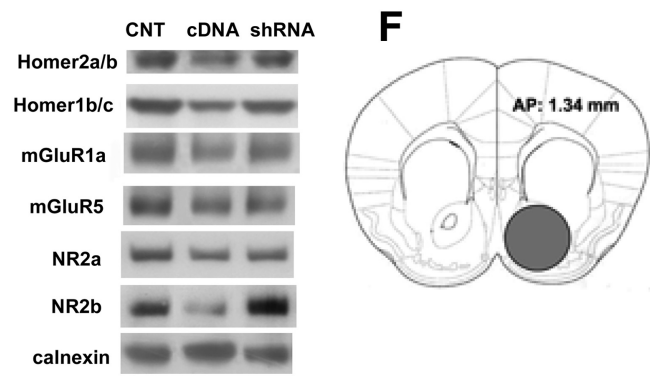

Figure 5. Glutamate anomalies in the NAC elicited by AAV-mediated manipulations of mPFC Homer2b levels. $A$, Summary of the effects of an intra-mPFC infusion of our control vectors (Control; $n=8)$, cDNA-Homer2b (cDNA; $n=6)$ or shRNA-Homer $2 b$ ( $\operatorname{shRNA} n=7$ ) upon the time course of change in extracellular glutamate levels within the NAC during baseline (time $\times 60-0 \mathrm{~min}$ ) and after a $15 \mathrm{mg} / \mathrm{kg}$, i.p., injection of cocaine (arrow). Although neither Control nor robust increase that persisted for the duration of the microdialysis session. $\boldsymbol{B}$, Data from $\boldsymbol{A}$, expressed as a percentage change from the average baseline values to better illustrate the impact of intra-mPFC CDNA infusion upon cocaine-induced microdialysis study demonstrating no change in the clearance of glutamate from the probe (slope) within the NAC by $7-10 / A A V)$. D, Summary of the placements of the microdialysis probes within the NAC of mice tested for intra-mPFC AAV-mediated changes in basal extracellular glutamate content by no net-flux microdialysis procedures $(\boldsymbol{C})$. $\boldsymbol{E}$, Representative immunoblots and summary of the change in protein expression within the NAC after the different intrarepresentative immunoblots for the total protein levels of Homer2a/b, Homer1b/c, mGluR1, mGluR5, NR2a, NR2b, and calnexin (loading control). For $\boldsymbol{E},{ }^{*} p<0.05$ versus CNT, ${ }^{\#} p<0.05$ versus other two AAV treatments, LSD post hoc tests. $\boldsymbol{F}$ (c) of the region within the NAC dissected out for determination of intra-mPFC AAV-mediated changes in glutamate receptor and Homer protein expression. All data represent the mean \pm SEM of the numbers of animals indicated in

pression (compare Figs. 5A, 3A), and the increase in cocaine CPP exhibited by Homer2b overexpressing mice was associated with "cocaine-like" anomalies in NAC extracellular glutamate levels (Fig. 4), we next assayed for the effects of mPFC Homer1c knockdown upon basal and cocaine-stimulated glutamate release in the NAC. mPFC Homer1c knockdown reduced NAC extracellular glutamate levels whether assayed by conventional microdialysis (GFP: $2.65 \pm 0.63$ versus Homer1c-shRNA: $1.26 \pm 0.19 \mathrm{ng} / \mathrm{sam}-$ ple; $\left.t_{(18)}=2.1, p=0.05\right)$ or by no net-flux microdialysis approaches (Fig. $5 C)\left(y=0 ; t_{(11)}=2.98, p=0.01\right)$. Moreover, the no net-flux study failed to reveal an effect of mPFC Homer1c 
Table 1. Summary of the relation between the relative expression of isoforms

\begin{tabular}{|c|c|c|c|c|c|c|c|}
\hline \multirow[b]{2}{*}{ Manipulation } & \multirow{2}{*}{$\begin{array}{l}\text { Relative Homer expression } \\
\text { in } \mathrm{mPFC}\end{array}$} & \multicolumn{2}{|c|}{ Basal glutamate content } & \multicolumn{2}{|c|}{$\begin{array}{l}\text { Cocaine-stimulated } \\
\text { release }\end{array}$} & \multirow{2}{*}{$\begin{array}{l}\text { Cocaine } \\
\text { reward }\end{array}$} & \multirow{2}{*}{$\begin{array}{l}\text { Cocaine } \\
\text { locomotion }\end{array}$} \\
\hline & & $\mathrm{mPFC}$ & NAC & $\mathrm{mPFC}$ & NAC & & \\
\hline Repeated i.p. cocaine & Homer2 $>$ Homer $^{a}$ & $-^{b}$ & $\downarrow^{c}$ & $\uparrow^{b}$ & $\uparrow c$ & $\uparrow^{d}$ & $\uparrow e$ \\
\hline Repeated i.v. cocaine & Homer2 $>$ Homer $1^{f, g}$ & $\downarrow^{h}$ & $\downarrow c$ & $\uparrow g$ & $\uparrow c$ & $\uparrow c$ & Mixed $^{i}$ \\
\hline Homer1 KO & Homer2 > Homer1 & $\uparrow j, k$ & $\downarrow^{\prime}$ & $\downarrow^{j, k}$ & $\uparrow !$ & $\uparrow l$ & $\uparrow^{j, k, l}$ \\
\hline mPFC CDNA-H2b & Homer2 > Homer1 & $\uparrow$ & $\downarrow$ & $\downarrow$ & $\uparrow$ & $\uparrow$ & - \\
\hline mPFC shRNA-H1c & Homer2 > Homer1 & n.d. & $\downarrow$ & n.d. & $\uparrow$ & $\uparrow$ & - \\
\hline Homer2 KO & Homer2 < Homer1 & -1 & $\downarrow l, m$ & -1 & $\uparrow^{\prime}$ & $\uparrow^{\prime}$ & $\uparrow^{\prime}$ \\
\hline mPFC shRNA-H2b & Homer2 < Homer1 & $\downarrow$ & - & $\uparrow$ & - & - & - \\
\hline mPFC CDNA-H1c & Homer2 < Homer1 & $\downarrow^{k}$ & n.d. & $\uparrow^{k}$ & n.d. & n.d. & $-^{k}$ \\
\hline
\end{tabular}

Data are reported as the relative expression of mPFC Homer1 versus Homer2 isoforms produced by either repeated cocaine experience (intraperitoneal or intravenous administration) or transgenic manipulations of Homer protein expression within drug-naive animals; and (1) the levels of basal extracellular glutamate within the MPFC and the NAC; (2) the change in extracellular glutamate levels within the mPFC and NAC produced by a cocaine challenge injection; (3) indices of cocaine reward or reinforcement (i.e., conditioned place-preference or intravenous cocaine self-administration); and (4) cocaine-stimulated locomotor behavior or locomotor sensitization. $\uparrow$ and $\downarrow$, Increase and decrease, respectively, relative to animals treated acutely with drug (for repeated intraperitoneal or intravenous cocaine administration), WT controls (for Homer1 and Homer2 KO mice), or animals infused with a control AAV (for CDNA and shRNA-infused animals); —, no change from aforementioned controls; CDNA-H2b, AAV carrying Homer2b cDNA; n.d., not determined.

${ }^{a}$ Ary and Szumlinski (2007).

${ }^{b}$ Williams and Steketee (2004).

'Baker et al. (2003).

'Lett et al. (1989).

${ }^{e}$ Vanderschuren and Kalivas (2000).

${ }^{f}$ Gould et al. (submitted).

${ }^{9}$ Ben-Shahar et al. (2012).

${ }^{h}$ Ben-Shahar et al. (2013).

'Ben-Shahar et al. (2004).

jSzumlinski et al. (2005a).

${ }^{k}$ Lominac et al. (2005).

'Szumlinski et al. (2004).

${ }^{m}$ Szumlinski et al. (2005b).

knockdown upon glutamate clearance as indicated by no group difference in the slopes of the linear regressions for $(t$ test, $p>$ $0.05)$. Thus, mPFC Homer1c knockdown produced effects upon basal NAC extracellular glutamate levels that mirrored those produced by mPFC Homer2b overexpression (Fig. 4).

Further similarities between Homer2-overexpressing and Homerlc-underexpressing mice were noted with regards to the magnitude of cocaine-elicited glutamate release within the NAC (Fig. 5D). An analysis of the raw glutamate levels (ng/sample) indicated a significant interaction between Homer1c knockdown and time that followed essentially the same pattern as that exhibited by Homer2b overexpressing animals in Figure $4 B$ (AAV X Time: $\left.F_{(11,176)}=3.17, p=0.001\right)$. To more clearly appreciate the similarity in effect, the neurochemical data for this experiment were normalized to baseline and this transformation revealed a marked rise in NAC glutamate levels in Homer1c knockdown animals, but no change in glutamate in controls $\left(F_{(11,176)}=2.68\right.$, $p=0.003)$. Thus, the effects of mPFC Homer $2 \mathrm{~b}$ overexpression upon both basal glutamate levels and cocaine-stimulated glutamate release within the NAC are recapitulated by $\mathrm{mPFC}$ Homer1c knockdown, with both transgenic strategies producing a NAC glutamate phenotype that resembles that of a cocaineexperienced animal (Pierce et al., 1996; Baker et al., 2003; McFarland et al., 2003; Szumlinski et al., 2006). These data strengthen the notion that an imbalance in CC-Homer1 and Homer2 proteins within the MPFC may contribute to anomalies in corticoaccumbens glutamate transmission associated with a high cocaine-seeking phenotype.

\section{Discussion}

Altered Homer function may contribute to dysregulated corticoaccumbens glutamate transmission observed in animal models of addiction (Szumlinski et al., 2008a; Knackstedt et al., 2010a,b; Ghasemzadeh et al., 2011). Cocaine withdrawal imbalances
Homer 1 and Homer 2 isoforms within the mPFC (Ary and Szumlinski, 2007) (Gould et al., submitted), but the functional relevance of this imbalance is not known. Herein, we show that increasing the relative expression of Homer2 versus Homer1 within the $\mathrm{mPFC}$ results in anomalous glutamate function within both the cell body and terminal regions of the corticoaccumbens pathway in drug-naive animals and, importantly, in heightened cocaine preference.

\section{Homer2 regulation of extracellular glutamate within the $\mathrm{mPFC}$}

Homer proteins regulate various aspects of corticoaccumbens glutamate transmission, including in vivo levels of extracellular glutamate (Table 1) (Szumlinski et al., 2008a). Thus, Homer1 deletion elevates mPFC basal extracellular glutamate content and prevents cocaine-induced increases in mPFC glutamate (Table 1), whereas overexpression of mPFC Homer1c in wild-type (WT) mice potentiates cocaine-induced glutamate release in $\mathrm{mPFC}$ (Lominac et al., 2005). In contrast, mPFC knockdown of Homer2b reduces basal mPFC glutamate and facilitates cocaineelicited glutamate release (Fig. 3), in essence producing a profile of mPFC glutamate anomalies akin to those produced by $\mathrm{mPFC}$ Homer1c overexpression (Table 1), suggesting opposing roles for constitutively expressed Homer1 and Homer2 gene products in regulating mPFC glutamate. Furthermore, elevating mPFC Homer2b expression produces an $\mathrm{mPFC}$ extracellular glutamate profile indistinguishable from that of Homer $1 \mathrm{KO}$ mice (Table 1). The inverse relation between basal extracellular levels of mPFC glutamate and the capacity of cocaine to evoke glutamate release within this region, likely relates to the relative amount of glutamate tone upon Group2 mGluR autoreceptors (Xi et al., 2002), but could also involve Homer-mediated occlusion of $\mathrm{Vca}_{2 . \mathrm{X}}$ regulation by Group1 mGluRs (Beqollari and Kammermeier, 2013) (see below). Finally, we want to note that the bidirectional regu- 
lation of basal glutamate by AAV-mediated manipulations of $\mathrm{mPFC}$ Homer2b levels suggests that the failure of Homer2 deletion to affect mPFC glutamate content (Szumlinski et al., 2004) likely reflects some developmental compensation(s), secondary to gene deletion.

How Homer deletion alters glutamate receptor expression within PFC is not known. Homer1 or Homer2 deletion was reported to not influence the surface expression of mGluR1/5 within subthalamic nucleus or globus pallidus when assessed by electron microscopy (Kuwajima et al., 2007). However, Homer2 KO mice exhibit reduced mGluR1 and NR2 NMDA receptor subunit expression within the NAC (Szumlinski et al., 2004, 2005b). The present immunoblotting data for the mPFC (Fig. 2) further the notion that transgenic Homer manipulations can influence the expression of glutamate receptors in vivo. As stimulation of Group1 mGluRs within the mPFC is sufficient to elicit glutamate release within this region, but is not necessary for maintaining basal extracellular glutamate content (Melendez et al., 2005), changes in total expression of these receptors can affect local glutamate levels. Still, the source of glutamate within mPFC affected by AAV-mediated changes in Homer2b expression remains to be determined and could include projections from basolateral amygdala, contralateral PFC, ventral tegmental area, hypothalamus-basal forebrain, brainstem, hippocampus, or different thalamic nuclei (Heidbreder and Groenewegen, 2003). Nevertheless, the present data provide novel evidence that Homer2 regulates both basal and cocaine-stimulated changes in $\mathrm{mPFC}$ extracellular glutamate in a manner opposite that of CCHomer1 isoforms (Table 1). Thus, drug-induced imbalances in Homer1 versus Homer2 expression within mPFC (Ary and Szumlinski, 2007) (Gould et al., submitted) has functional relevance for both basal and drug-stimulated excitatory neurotransmission within a brain region exhibiting metabolic anomalies in addiction (Goldstein and Volkow, 2011).

\section{mPFC imbalance in Homer2 versus Homer 1 promotes cocaine preference: link to NAC glutamate}

Although our Homer2b constructs bidirectionally affected mPFC glutamate (Table 1), only cDNA-Homer2b infusion influenced cocaine CPP. Moreover, the Homer2b-mediated potentiation of cocaine preference was recapitulated on mPFC Homer 1c knockdown (Fig. 6). These observations, coupled with the fact that heightened cocaine preference and intake is observed in Homer2 KO mice (Szumlinski et al., 2004), indicate that imbalances in Homer1-Homer2 expression within mPFC is sufficient, but not necessary, to promote heightened sensitivity to cocaine's conditioned rewarding properties. However, it should be noted that because the AAV constructs were infused before conditioning, the psychological process(es) leading to greater place preference require further study.

The fact that mPFC Homer2 knockdown failed to reduce cocaine $\mathrm{CPP}$ was not surprising; Homer2 $\mathrm{KO}$ mice exhibit greater cocaine CPP, and self-administer more cocaine, than their WT controls (Szumlinski et al., 2004). Although Homer1 and Homer $2 \mathrm{KO}$ mice differ in terms of glutamate anomalies in mPFC (Table 1), both KO strains exhibit similar glutamate anomalies within the NAC shell (Table 1) that were theorized previously to contribute to their heightened cocaine sensitivity (Szumlinski et al., 2004). Remarkably, an AAV-mediated imbalance in primarily ventromedial PFC (vmPFC) Homer $1 / 2$ expression of drug-naive mice was sufficient to produce a large number of cocaine-associated glutamate anomalies within the NAC (Fig. 5). Of note, mPFC Homer2 overexpres-
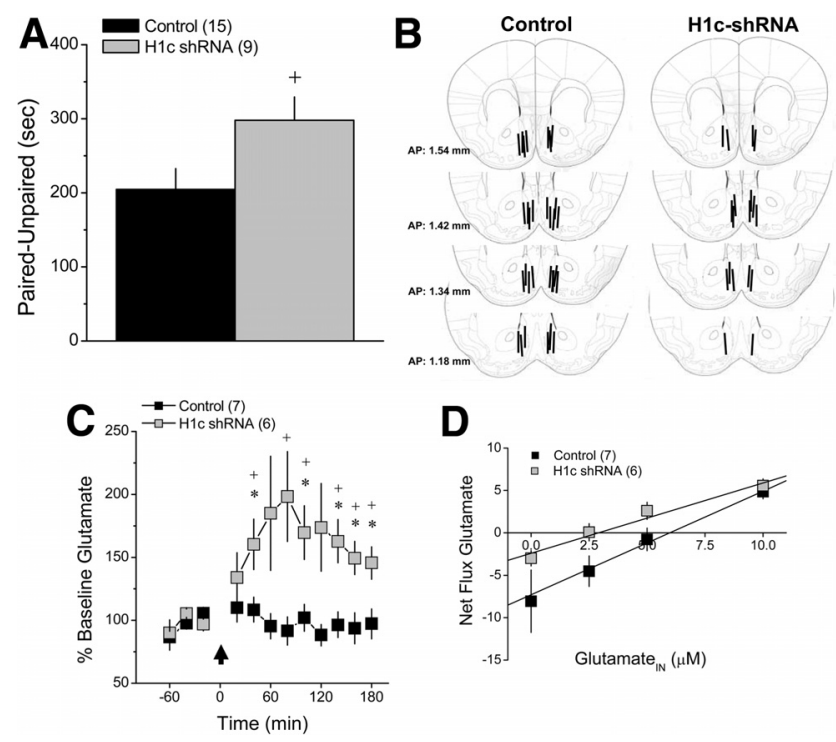

Figure 6. $\mathrm{mPFC}$ knockdown of Homer1c potentiates cocaine-seeking and produces anomalies in NAC extracellular gluatamate. $\boldsymbol{A}$, Summary of difference in the time spent (in seconds) on the cocaine-paired versus cocaine-unpaired side of the place-conditioning apparatus ( 0 ccupancy Difference) exhibited by mice infused intra-mPFC with AAVs carrying a GFP control vector (Control; $n=15$ ) or shRNA-Homer1c (H1c shRNA; $n=9$ ) on a post-conditioning test, after four pairings of $15 \mathrm{mg} / \mathrm{kg}$ cocaine. Homer1c knockdown within the MPFC increased the magnitude of the CPP. ${ }^{+} p<0.05$ versus Control ( $t$ test). $B$, Summary of the placements of the microdialysis probes within the NAC of mice tested for intra-mPFCAAV-mediated changes in extracellular glutamate. The probes were localized primarily to the shell subregion or the interface between the shell and core subregions. $\boldsymbol{C}$, Summary of the effects of an intra-mPFC infusion of our control vector or shRNA-Homer1c upon the time course of change in extracellular glutamate levels within the NAC during baseline (time $\times 60-0 \mathrm{~min}$ ) and after a $15 \mathrm{mg} / \mathrm{kg}$, i.p., injection of cocaine (arrow), with the data expressed as a percentage change from the average baseline values for clarity ( $n=7-8)$. Homer1c knockdown facilitated the capacity of acute cocaine to elevate NAC levels of extracellular glutamate. ${ }^{*} p<0.05$ versus average baseline (paired $t$ tests with corrections for multiple comparisons; ${ }^{+} p<0.05$ versus (ontrol; unpaired $t$ tests). $\boldsymbol{D}$, Summary of the results of a quantitative in vivo microdialysis study demonstrating no change in the clearance of glutamate from the probe (slope) within the NAC by intra-mPFC Homer1c knockdown, but a significant shift to the left in the point of no net glutamateflux $(y=0)$ in shRNA-infused mice $(n=7-8)$. All the data in $\boldsymbol{A}-\boldsymbol{D}$ represent the mean \pm SEM of the numbers of animals indicated in parentheses in each panel.

sion lowered NAC levels of both Homer1b/c and Homer2a/ $\mathrm{b}$-an effect that cannot readily be explained by anterograde transport of our AAV-cDNA construct to glutamate terminals in this region. However, as the entire NAC was sampled for immunoblotting, the subregional localization of the cDNAmediated reductions in Homer $1 / 2$ and/or glutamate receptor expression within the NAC cannot be discerned. Nevertheless, mimicking the imbalance in vmPFC Homer $1 / 2$ expression observed during withdrawal from a history of repeated cocaine (Ary and Szumlinski, 2007) (Gould et al., submitted) is sufficient to augment cocaine $\mathrm{CPP}$ and produce a protein profile within the entire NAC that resembles, in large part, those observed within either the core and/or shell subregion of the NAC of chronic cocaine-treated animals (Table 1).

Glutamate levels were sampled from the NAC shell in this study, as we previously observed a positive relation between the magnitude of cocaine CPP in mice and cocaine-elicited increases in extracellular glutamate within this subregion (Szumlinski et al., 2007; Penzner et al., 2008). The NAC shell receives glutamatergic projections from both the ventral prelimbic (vPL) and the infralimbic (IL) subdivisions of the 
mPFC (Heidbreder and Groenewegen, 2003), which is in line with our observation that Homer2b cDNA overexpression primarily within the vPL and the vPL-IL interface (Fig. $2 A$ ) impacted extracellular glutamate within the NAC shell (Fig. 5). The vmPFC-NAC shell glutamatergic projections are theorized to regulate behavioral flexibility, as well as guide behavior in response to the integration of internal physiological states with salient cues in the environment (Heidbreder and Groenewegen, 2003). Although one study reported a potentiation of cocaine reinstatement by pharmacological IL inhibition (Peters et al., 2008), considerable evidence from both lesion and neuropharmacological studies indicate either no effect upon (cf., Kalivas and McFarland, 2003), or an attenuation of, cocaine reinstatement by inactivation of more ventral aspects of the PFC (Capriles et al., 2003; Koya et al., 2009). Perhaps most relevant to this report, lesions of ventral PFC disrupt also cocaine CPP (Tzschentke and Schmidt, 1998). The results of this, and our previous studies using AAVmediated Homer gene transfer to the NAC shell (Szumlinski et al., 2004), are consistent with an important role for excitatory neurotransmission within the vmPFC-NAC shell projection in drug-related learning and the conditioned control drugpaired stimuli exert upon behavior. Importantly, these results provide evidence that drug-induced or idiopathic alterations in the expression of CC-Homer1 and CC-Homer2 isoforms within either the cell body or terminal regions of this projection render an animal more sensitive to the conditioned motivational properties of drug-paired stimuli that likely increase addiction vulnerability.

\section{Hypothetical mechanisms underpinning the opposing actions of Homer 1 and Homer2 upon mPFC glutamate}

How postsynaptically localized Homer proteins regulate extracellular glutamate levels in vivo is unknown. Although NAC basal extracellular glutamate is maintained primarily by nonvesicular mechanisms involving the cystine-glutamate antiporter (system Xc), and to a lesser extent vesicular mechanisms (Baker et al., 2003), those maintaining basal glutamate levels within the mPFC are unresolved (Melendez et al., 2005). Homer2 deletion lowers NAC levels of $\mathrm{X}_{\mathrm{c}}-$, and impairs system $\mathrm{X}_{\mathrm{c}}-$ function in vivo (Szumlinski et al., 2004). However, system $\mathrm{X}_{\mathrm{c}}$ - does not contain any obvious consensus sequence for Homer binding (Szumlinski et al., 2004) and our AAVs are neurotrophic (Klugmann and Szumlinski, 2008), whereas system $X_{c}-$ is expressed primarily by glial cells (Cho and Bannai, 1990). Thus, it is unlikely that any interactions between Homers and system $\mathrm{X}_{\mathrm{c}}$ - are direct and the details of the interaction and how they might relate to the regulation of extracellular glutamate in vivo are yet unknown.

Different Homer isoforms exhibit a very high degree of sequence homology within their $N$-terminal EVH1 domains required for interactions with their various cellular effectors (cf., Shiraishi-Yamaguchi and Furuichi, 2007), including diacylglycerol lipase- $2 \alpha$ (Jung et al., 2007). As such, the opposing influence of Homer1 and Homer2 upon mPFC extracellular glutamate likely relates to their divergent C-terminal domains. Indeed, Homer2 is more occlusive than Homer1 with respect to Group1 mGluR's efficiency to signal to voltage-gated ion channels in vitro (Kammermeier and Worley, 2007) and Homer2 occludes Group1 mGluRmediated inhibition of $\mathrm{Ca}_{\mathrm{v} 2.2}$ and $\mathrm{Cav}_{2.3}$ function (Kammermeier et al., 2000; Won et al., 2009; Kammermeier, 2008; Beqollari and Kammermeier, 2013). Thus, the rise in mPFC basal extracellular levels of glutamate produced by $\mathrm{mPFC}$ Homer2 overexpression might involve disinhibition of voltagegated calcium channels, resulting in an increase in vesicular glutamate. Conversely, as mPFC Homer2 overexpression reduced both Homerlb/c and Homer2 expression within the NAC (Fig. $5 E$ ), the reduced basal NAC extracellular glutamate levels might reflect a heightened capacity of Group 1 mGluRs to inhibit $\mathrm{Ca}_{\mathrm{v} 2 . \mathrm{x}}$ function and reduce vesicular, rather than nonvesicular, release.

\section{Conclusions}

An increase in the relative expression of Homer2 versus Homer1 isoforms within the ventromedial PFC heightens cocaine preference and produces a number of glutamate anomalies within the NAC shell that are known to render an animal more sensitive to the rewarding and reinforcing properties of cocaine. If relevant to humans, the present data pose idiopathic or drug-induced imbalances in mPFC Homer1/2 expression as a molecular trigger to addiction vulnerability.

\section{References}

Ary AW, Szumlinski KK (2007) Regional differences in the effects of withdrawal from repeated cocaine upon homer and glutamate receptor expression: a two-species comparison. Brain Res 1184:295-305. CrossRef Medline

Baker DA, McFarland K, Lake RW, Shen H, Tang XC, Toda S, Kalivas PW (2003) Neuroadaptations in cystine-glutamate exchange underlie cocaine relapse. Nat Neurosci 6:743-749. CrossRef Medline

Ben-Shahar O, Obara I, Ary AW, Ma N, Mangiardi MA, Medina RL, Szumlinski KK (2009) Extended daily access to cocaine results in distinct alterations in homer $1 \mathrm{~b} / \mathrm{c}$ and NMDA receptor subunit expression within the medial prefrontal cortex. Synapse 63:598-609. CrossRef Medline

Ben-Shahar OM, Szumlinski KK, Lominac KD, Cohen A, Gordon E, Ploense KL, DeMartini J, Bernstein N, Rudy NM, Nabhan AN, Sacramento A, Pagano K, Carosso GA, Woodward N (2012) Extended access to cocaine self-administration results in reduced glutamate function within the medial prefrontal cortex. Addict Biol 17:746-757. CrossRef Medline

Ben-Shahar O, Sacramento AD, Miller BW, Webb SM, Wroten MG, Silva HE, Caruana AL, Gordon EJ, Ploense KL, Ditzhazy J, Kippin TE, Szumlinski KK (2013) Deficits in ventral prefrontal cortex Group1 metabotropic glutamate receptor function mediate resistance to extinction during protracted withdrawal from an extensive history of cocaine selfadministration. J Neurosci 33:495-506a. CrossRef Medline

Beqollari D, Kammermeier PJ (2013) The interaction between mGluR1 and the calcium channel Cav2.1 preserves coupling in the presence of long Homer proteins. Neuropharmacology 66:302-310. CrossRef Medline

Bimonte HA, Nelson ME, Granholm AC (2003) Age-related deficits as working memory load increases: relationships with growth factors. Neurobiol Aging 24:37-48. CrossRef Medline

Capriles N, Rodaros D, Sorge RE, Stewart J (2003) A role for the prefrontal cortex in stress- and cocaine-induced reinstatement of cocaine seeking in rats. Psychopharmacology 168:66-74. CrossRef Medline

Cho Y, Bannai S (1990) Uptake of glutamate and cysteine in C-6 glioma cells and in cultured astrocytes. J Neurochem 55:2091-2097. CrossRef Medline

Cozzoli DK, Goulding SP, Zhang PW, Xiao B, Hu JH, Ary AW, Obara I, Rahn A, Abou-Ziab H, Tyrrel B, Marini C, Yoneyama N, Metten P, Snelling C, Dehoff MH, Crabbe JC, Finn DA, Klugmann M, Worley PF, Szumlinski KK (2009) Binge drinking upregulates accumbens mGluR5-Homer2PI3K signaling: functional implications for alcoholism. J Neurosci 29: 8655-8668. CrossRef Medline

Cozzoli DK, Courson J, Caruana AL, Miller BW, Greentree DI, Thompson AB, Wroten MG, Zhang PW, Xiao B, Hu JH, Klugmann M, Metten P, Worley PF, Crabbe JC, Szumlinski KK (2012) Nucleus accumbens mGluR5-associated signaling regulates binge alcohol drinking under drinking-in-the-dark procedures. Alcohol Clin Exp Res 36:16231633. CrossRef Medline

Gass JT, Olive MF (2008) Glutamatergic substrates of drug addiction and alcoholism. Biochem Pharmacol 75:218-265. CrossRef Medline

Ghasemzadeh MB, Permenter LK, Lake R, Worley PF, Kalivas PW (2003) Homer1 proteins and AMPA receptors modulate cocaine-induced behavioural plasticity. Eur J Neurosci 18:1645-1651. CrossRef Medline 
Ghasemzadeh MB, Mueller C, Vasudevan P (2009a) Behavioral sensitization to cocaine is associated with increased glutamate receptor trafficking to the postsynaptic density after extended withdrawal period. Neuroscience 159:414-426. CrossRef Medline

Ghasemzadeh MB, Vasudevan P, Mueller C, Seubert C, Mantsch JR (2009b) Neuroadaptations in the cellular and postsynaptic group 1 metabotropic glutamate receptor mGluR5 and homer proteins following extinction of cocaine self-administration. Neurosci Lett 452:167-171. CrossRef Medline

Ghasemzadeh MB, Vasudevan P, Giles C, Purgianto A, Seubert C, Mantsch JR (2011) Glutamatergic plasticity in medial prefrontal cortex and ventral tegmental area following extended-access cocaine self-administration. Brain Res 1413:60-71. CrossRef Medline

Goldstein RZ, Volkow ND (2011) Dysfunction of the prefrontal cortex in addiction: neuroimaging findings and clinical implications. Nat Rev Neurosci 12:652-669. CrossRef Medline

Goulding SP, Obara I, Lominac KD, Gould AT, Miller BW, Klugmann M, Szumlinski KK (2011) Accumbens Homer2-mediated signaling: a factor contributing to mouse strain differences in alcohol drinking? Genes Brain Behav 10:111-126. CrossRef Medline

Hayashi MK, Ames HM, Hayashi Y (2006) Tetrameric hub structure of postsynaptic scaffolding protein homer. J Neurosci 26:8492-8501. CrossRef Medline

Heidbreder CA, Groenewegen HJ (2003) The medial prefrontal cortex in the rat: evidence for a dorso-ventral distinction based upon functional and anatomical characteristics. Neurosci Biobehav Rev 27:555-579. CrossRef Medline

Jung KM, Astarita G, Zhu C, Wallace M, Mackie K, Piomelli D (2007) A key role for diacylglycerol lipase-alpha in metabotropic glutamate receptordependent endocannabinoid mobilization. Mol Pharmacol 72:612-621. CrossRef Medline

Kalivas PW, McFarland K (2003) Brain circuitry and the reinstatement of cocaine-seeking behavior. Psychopharmacology 168:44-56. CrossRef Medline

Kalivas PW, Volkow ND (2011) New medications for drug addiction hiding in glutamatergic neuroplasticity. Mol Psychiatry 16:974-986. CrossRef Medline

Kammermeier PJ, Xiao B, Tu JC, Worley PF, Ikeda SR (2000) Homer proteins regulate coupling of group I metabotropic glutamate receptors to N-type calcium and M-type potassium channels. J Neurosci 20:72387245. Medline

Kammermeier PJ, Worley PF (2007) Homer la uncouples metabotropic glutamate receptor 5 from postsynaptic effectors. Proc Natl Acad Sci U S A 104:6055-6060. CrossRef Medline

Kammermeier PJ (2008) Endogenous homer proteins regulate metabotropic glutamate receptor signaling in neurons. J Neurosci 28:8560-8567. CrossRef Medline

Kapasova Z, Szumlinski KK (2008) Strain differences in alcohol-induced neurochemical plasticity: a role for accumbens glutamate in alcohol intake. Alcohol Clin Exp Res 32:617-631. CrossRef Medline

Klugmann M, Symes CW, Leichtlein CB, Klaussner BK, Dunning J, Fong D, Young D, During MJ (2005) AAV-mediated hippocampal expression of short and long homer 1 proteins differentially affect cognition and seizure activity in adult rats. Mol Cell Neurosci 28:347-360. CrossRef Medline

Klugmann M, Szumlinski KK (2008) Targeting homer genes using adenoassociated viral vector: lessons learned from behavioural and neurochemical studies. Behav Pharmacol 19:485-500. CrossRef Medline

Knackstedt LA, Kalivas PW (2009) Glutamate and reinstatement. Curr Opin Pharmacol 9:59-64. CrossRef Medline

Knackstedt LA, Melendez RI, Kalivas PW (2010a) Ceftriaxone restores glutamate homeostasis and prevents relapse to cocaine seeking. Biol Psychiatry 67:81-84. CrossRef Medline

Knackstedt LA, Moussawi K, Lalumiere R, Schwendt M, Klugmann M, Kalivas PW (2010b) Extinction training after cocaine self-administration induces glutamatergic plasticity to inhibit cocaine seeking. J Neurosci 30:7984-7992. CrossRef Medline

Koya E, Uejima JL, Wihbey KA, Bossert JM, Hope BT, Shaham Y (2009) Role of ventral medial prefrontal cortex in incubation of cocaine craving. Neuropharmacology 56 [Suppl 1]:177-185. CrossRef

Kuwajima M, Dehoff MH, Furuichi T, Worley PF, Hall RA, Smith Y (2007) Localization and expression of group I metabotropic glutamate receptors in the mouse striatum, globus pallidus, and subthalamic nucleus: regula- tory effects of MPTP treatment and constitutive homer deletion. J Neurosci 27:6249-6260. CrossRef Medline

Lett BT (1989) Repeated exposures intensify rather than diminish the rewarding effects of amphetamine, morphine, and cocaine. Psychopharmacology (Berl) 98:357-362. CrossRef Medline

Lominac KD, Oleson EB, Pava M, Klugmann M, Schwarz MK, Seeburg PH, During MJ, Worley PF, Kalivas PW, Szumlinski KK (2005) Distinct roles for different Homerl isoforms in behaviors and associated prefrontal cortex function. J Neurosci 25:11586-11594. CrossRef Medline

Lominac KD, Sacramento AD, Szumlinski KK, Kippin TE (2012) Distinct neurochemical adaptations within the nucleus accumbens produced by a history of self-administered vs noncontingently administered intravenous methamphetamine. Neuropsychopharmacology 37:707-722. CrossRef Medline

Madayag A, Kau KS, Lobner D, Mantsch JR, Wisniewski S, Baker DA (2010) Drug-induced plasticity contributing to heightened relapse susceptibility: neurochemical changes and augmented reinstatement in high-intake rats. J Neurosci 30:210-217. CrossRef Medline

McAlonan GM, Robbins TW, Everitt BJ (1993) Effects of medial dorsal thalamic and ventral pallidal lesions on the acquisition of a conditioned place preference: further evidence for the involvement of the ventral striatopallidal system in reward-related processes. Neuroscience 52:605-620. CrossRef Medline

McFarland K, Lapish CC, Kalivas PW (2003) Prefrontal glutamate release into the core of the nucleus accumbens mediates cocaine-induced reinstatement of drug-seeking behavior. J Neurosci 23:3531-3537. Medline

Melendez RI, Vuthiganon J, Kalivas PW (2005) Regulation of extracellular glutamate in the prefrontal cortex: focus on the cystine glutamate exchanger and group I metabotropic glutamate receptors. J Pharmacol Exp Ther 314:139-147. CrossRef Medline

Paxinos G, Franklin KBJ (2007) The mouse brain atlas in stereotaxic coordinates, Ed 3, San Diego: Academic.

Penzner JH, Thompson DL, Arth C, Fowler JK, Ary AW, Szumlinski KK (2008) Protracted "anti-addictive" effects of adolescent phenylpropanolamine exposure in C57BL/6J mice. Addict Biol 13:310-325. CrossRef Medline

Peters J, LaLumiere RT, Kalivas PW (2008) Infralimbic prefrontal cortex is responsible for inhibiting cocaine seeking in extinguished rats. J Neurosci 28:6046-6053. CrossRef Medline

Pierce RC, Bell K, Duffy P, Kalivas PW (1996) Repeated cocaine augments excitatory amino acid transmission in the nucleus accumbens only in rats having developed behavioral sensitization. J Neurosci 16 : 1550-1560. Medline

Porsolt RD, Le Pichon M, Jalfre M (1977) Depression: a new animal model sensitive to antidepressant treatments. Nature 266:730-732. CrossRef Medline

Schmidt HD, Pierce RC (2010) Cocaine-induced neuroadaptations in glutamate transmission: potential therapeutic targets for craving and addiction. Ann N Y Acad Sci 1187:35-75. CrossRef Medline

Sesack SR, Pickel VM (1992) Prefrontal cortical efferents in the rat synapse on unlabeled neuronal targets of catecholamine terminals in the nucleus accumbens septi and on dopamine neurons in the ventral tegmental area. J Comp Neurol 320:145-160. CrossRef Medline

Shiraishi-Yamaguchi Y, Furuichi T (2007) The homer family proteins. Genome Biol 8:206. CrossRef Medline

Swanson CJ, Baker DA, Carson D, Worley PF, Kalivas PW (2001) Repeated cocaine administration attenuates group I metabotropic glutamate receptor-mediated glutamate release and behavioral activation: a potential role for homer. J Neurosci 21:9043-9052. Medline

Szumlinski KK, Dehoff MH, Kang SH, Frys KA, Lominac KD, Rohrer J, Klugmann M, Griffin W 3rd, Toda S, Champtiaux NP, Berry T, Tu JC, Shealy SE, During MJ, Middaugh LD, Worley PF, Kalivas PW (2004) Homer proteins regulate vulnerability to cocaine. Neuron 43:401-413. CrossRef Medline

Szumlinski KK, Lominac KD, Kleschen MJ, Oleson EB, Dehoff MH, Schwartz MK, Seeberg PH, Worley PF, Kalivas PW (2005a) Behavioural and neurochemical phenotyping of Homerl mutant mice: possible implications for schizophrenia. Genes Brain Behav 4:273-288. CrossRef Medline

Szumlinski KK, Lominac KD, Oleson EB, Walker JK, Mason A, Dehoff MH, Klugmann M, Cagle S, Welt K, During M, Worley PF, Middaugh LD, Kalivas PW (2005b) Homer2 is necessary for EtOH-induced neuroplasticity. J Neurosci 25:7054-7061. CrossRef Medline 
Szumlinski KK, Abernathy KE, Oleson EB, Klugmann M, Lominac KD, He DY, Ron D, During M, Kalivas PW (2006) Homer isoforms differentially regulate cocaine-induced neuroplasticity. Neuropsychopharmacology 31:768-777. CrossRef Medline

Szumlinski KK, Liu A, Penzner JH, Lominac KD (2007) Protracted "proaddictive" phenotype produced in mice by pre-adolescent phenylpropanolamine. Neuropsychopharmacology 32:1760-1773. CrossRef Medline

Szumlinski KK, Ary AW, Lominac KD (2008a) Homers regulate druginduced neuroplasticity: implications for addiction. Biochem Pharmacol 75:112-133. CrossRef Medline

Szumlinski KK, Ary AW, Lominac KD, Klugmann M, Kippin TE (2008b) Accumbens Homer2 overexpression facilitates alcohol-induced neuroplasticity in C57BL/6J mice. Neuropsychopharmacology 33:13651378. CrossRef Medline

Tzschentke TM, Schmidt WJ (1998) Discrete quinolinic acid lesions of the rat prelimbic medial prefrontal cortex affect cocaine- and MK-801-, but not morphine- and amphetamine-induced reward and psychomotor activation as measured with the place preference conditioning paradigm. Behav Brain Res 97:115-127. CrossRef Medline
Vanderschuren LJ, Kalivas PW (2000) Alterations in dopaminergic and glutamatergic transmission in the induction and expression of behavioral sensitization: a critical review of preclinical studies. Psychopharmacology (Berl) 151:99-120. CrossRef Medline

Williams JM, Steketee JD (2004) Cocaine increases medial prefrontal cortical glutamate overflow in cocaine-sensitized rats: a time course study. Eur J Neurosci 20:1639-1646. CrossRef Medline

Wolf ME, Ferrario CR (2010) AMPA receptor plasticity in the nucleus accumbens after repeated exposure to cocaine. Neurosci Biobehav Rev 35: 185-211. CrossRef Medline

Won YJ, Puhl HL 3rd, Ikeda SR (2009) Molecular reconstruction of mGluR5a mediated endocannabinoid signaling cascade in single rat sympathetic neurons. J Neurosci 29:13603-13612. CrossRef Medline

Xi ZX, Ramamoorthy S, Baker DA, Shen H, Samuvel DJ, Kalivas PW (2002) Modulation of group II metabotropic glutamate receptor signaling by chronic cocaine. J Pharmacol Exp Ther 303:608-615. CrossRef Medline 